\title{
Five methods to interpret field measurements of energy fluxes over a micro-sprinkler-irrigated mango orchard
}

\author{
A. H. de C. Teixeira $\cdot$ W. G. M. Bastiaanssen
}

Received: 30 October 2009/Accepted: 13 December 2010

(C) Springer-Verlag 2010

\begin{abstract}
Energy balance measurements were carried out in a mango orchard during two growing seasons in the semi-arid region of Brazil. The actual evapotranspiration (ET) was acquired by eddy correlation (EC) and Bowen ratio energy balance (BR) techniques. The daily energy balance closure in the EC measurements showed an average gap of $12 \%$, with a root mean square error (RMSE) of $1.7 \mathrm{MJ} \mathrm{m}^{-2} \mathrm{~d}^{-1}$. Three different correction procedures were tested for closing the energy balance from the EC system: (1) the surface energy balance residual method (RES), (2) the Bowen ratio determined from the EC fluxes, the combination approach (EC_BR), and (3) a new regression energy balance closure technique (REG). All closing energy balance methods presented good correlation with the direct EC measurements, but the trends were not similar. The latent heat fluxes estimated by the BR method- $\lambda E_{\mathrm{BR}}$-were higher than those from the direct EC measurements- $\lambda E_{\mathrm{EC}}$. When using the RES method, the half-hour $\lambda E_{\mathrm{EC}}$ measurements represented around $88 \%$ of the $\lambda E_{\mathrm{RES}}$ values, as the uncertainties of net radiation$R_{\mathrm{n}}$-and soil heat fluxes- $G$ - are propagated into the RES
\end{abstract}

Communicated by S. Ortega-Farias.

A. H. de C. Teixeira ( $₫)$

Embrapa Semiárido, P.O. Box 23, Petrolina, PE 56302-970, Brazil

e-mail: heribert@cpatsa.embrapa.br

W. G. M. Bastiaanssen

WaterWatch, Generaal Foulkesweg 28,

6703 BS Wageningen, The Netherlands

W. G. M. Bastiaanssen

Delft University of Technology, Stevinweg 1,

2600 GA Delft, The Netherlands method. The latent heat flux derived from the combination approach- $\lambda E_{\mathrm{EC} \_\mathrm{BR}}$-also brings these uncertainties, being the agreements comparable with those for RES method. It was therefore concluded that a single correction method for EC measurements considering only the latent and sensible heat fluxes does not exist. A new way to solve the lack of energy balance closure from EC techniques was tested by means of a curve fitting, the REG method. Considering the REG corrections applied to the energy balance components involving all periods of the day and the average conditions of the two growing seasons, half-hour values of $\lambda E_{\mathrm{EC}}$ were overmeasured by $18 \%, H_{\mathrm{EC}}$ was undermeasured by $17 \%$, and $G$ values required a correction of $466 \%$. The REG method appeared promising because it considers different weights for all energy balance components in the optimization process. Taking the REG results for the drier second growing season as a reference, it was concluded that seasonal ET values by the other methods in mango orchard ranged from 7 to $28 \%$ higher, showing that turbulent flux measurements lack accuracy for executing on-farm watersaving programmes and calibrating transient soil water flow models.

\section{Introduction}

Actual evapotranspiration (ET) from irrigated crops is receiving renewed attention because of the increasing competition of crop water use with other sectors. Reduction in ET in irrigation systems is thought to be a viable solution for achieving water savings in overexploited river basins (Bastiaanssen et al. 2008; Teixeira 2009). Deficit irrigation experiments saves water, enhances stream flow and does not necessarily affect crop production (Fereres and Soriana 2007). 
The highest yield levels per unit of water use $\left(\mathrm{kg} \mathrm{m}^{-3}\right)$ are obtained at mild water stress conditions, and to establish these conditions, it is first necessary to know actual and potential ET. Modelling of ET processes is therefore getting new impetus; hydrological, soil physical and remote sensing models are used to determine optimum levels of water use (Bastiaanssen et al. 2007). All these advanced models require careful calibration and validation with field data (e.g. Ahmad et al. 2002; Droogers et al. 2010). Standardized and simplified methods for crop ET computations such as described in FAO 56 (Allen et al. 1998) require experiments over extend periods of time. Many of them have shown accurate results in a wide range of agricultural situations. However, their application to sparse crops like orchards is generally more difficult than for uniform field crops.

In the widely recognized energy balance non-closure problem in eddy correlation (EC) systems, few intercomparisons have focused on the role of data-processing schemes between EC measurements and the forcing closure methods in irrigated orchards. Some research in different kind of vegetation has shown that differences are reduced if the components of the energy balance are averaged over longer time periods (Dugas et al. 1991; Unland et al. 1996; Spano et al. 2000; Beringer and Tapper 2000; Olejnik et al. 2001; Azevedo et al. 2003; van Dijk et al. 2004a, b; Ortega-Farias et al. 2007; Simmons et al. 2007). However, all components of the simplified energy balance equation have their own source of errors, being important to apply a method where the additional corrections for net radiation $\left(R_{\mathrm{n}}\right)$ and soil heat flux $(G)$ are included when considering short timescale (Allen 2008).

Traditionally, ET has been measured with lysimetery (Doorenbos and Pruitt 1977; Wright 1982; Jensen et al. 1990; Allen et al. 1998). For orchards, the size of the trees and the need to sample a representative area means that lysimeters are not practical. Due to large rooting depths, the ET measurements in trees are very difficult to be made with weighing lysimeters and soil water balance. There are considerable uncertainties related to the measurements of the soil depth affected by root water uptake, percolation, runoff and capillarity rise (Teixeira et al. 2008a). According to Rana et al. (2005), the use of the soil water balance to determine ET is not ideal, especially in the case of sparse crops and in regions subjected to semi-arid climates. In some occasions, transpiration can be measured directly with the heat pulse velocity-sap flow technique, which has been applied in vineyards (e.g. Yunusa et al. 2004) and olive groves (e.g. Testi et al. 2006). This method together with soil evaporation measurements may give good results, but in orchards, it is affected by individual tree variability and the upscaling from trees to a stand or block is problematic.
During the twenty-first century, lysimeters have been replaced by several micro-meteorological techniques for ET calculations, being the use of EC systems the most common (Wilson et al. 2002), which directly measure the latent $(\lambda E)$ and sensible $(H)$ heat fluxes. Examples of their applications in agricultural and natural ecosystems are published by Oliver and Sene (1992), Sene (1994), Trambouze et al. (1998), Ohta et al. (2001), Cleverly et al. (2002), Wilson et al. (2002), Humphreys et al. (2003), Lund and Soegaard (2003), Prueger et al. (2004), Vilalolobos et al. (2004), Testi et al. (2004), Simmons et al. (2007), Hiyama et al. (2007), Teixeira et al. (2008a, b). According to all these EC results, the energy balance is usually not closed, which poses a serious problem for achieving progresses in the general knowledge of crop ET variability.

The lack of the energy balance closure in EC systems can be related to malfunctions of the sensors during rainfall conditions; instrumental maintenance; neglected energy sinks; heat storage in the top soil; loss of low and/or high frequency contributions to the turbulent heat fluxes; advection of scalars; different correction algorithms used to process the data; flux divergence in the boundary layer; non-uniform footprint; non-representative sensing of $R_{\mathrm{n}}$ and $G$; proper average times; and when neglecting of the energy stored in the tree canopies for accounting for the available energy partitioning (Paw et al. 2000; Baldocchi et al. 2001; Scott et al. 2003a, b; Papale et al. 2006; Wolf et al. 2008; Castellvi et al. 2008). Yet, after applying algorithms for general corrections to $\lambda E_{\mathrm{EC}}$ and $H_{\mathrm{EC}}$, energy balance closure errors still remain in the other energy balance components (Allen 2008).

The Bowen ratio (BR) method forces the energy balance closure and requires cheaper instruments than EC systems. BR measurements are very useful when $\lambda E$ and $H$ cannot be measured directly. Examples of applications of BR method are found in Heilman et al. (1996), Ahmad et al. (2002), Inman-Bamber and McGlinchey (2003), Lee et al. (2004), Teixeira et al. (Teixeira et al. 2007, 2008b), and Savage et al. (2009). Other advantage of the BR method over EC measurements is its ease of use, as the simple theoretical basis requires relatively modest instruments. The BR fluxes are obtained, however, from indirect measurements, and the high degree of turbulent mixing over sparse crops promotes small temperature and humidity gradients demanding high measurements resolution and accuracy. Another important disadvantage is that the uncertainties of $R_{\mathrm{n}}$ and $G$ measurements are propagated into the BR method.

The assumption of the similarity for the diffusion coefficients for heat $\left(K_{\mathrm{h}}\right)$ and vapour $\left(K_{\mathrm{v}}\right)$ is implicitly imbedded in the BR technology. An earlier study from Denmead and McIlroy (1970) showed that the assumption of $K_{\mathrm{h}}=K_{\mathrm{v}}$ is 
acceptable for neutral to moderately unstable conditions over smooth surfaces; however, Verma et al. (1978) reported data evidencing $K_{\mathrm{h}}>K_{\mathrm{v}}$ for stable conditions. At night or under advective conditions, the negative values for Bowen ratio promote large relative error in the energy fluxes resulting in inaccuracies of ET values. In addition, the BR technique is not suitable for dry areas, and the simplified energy balance equation, frequently used, states that $R_{\mathrm{n}}$ is redistributed over $H_{\mathrm{BR}}, \lambda E_{\mathrm{BR}}$ and $G$, considering only vertical fluxes, ignoring the net rate at which energy is being transferred horizontally by advection and the heat stored or released in the canopies. These terms can be significant near the edges of tall trees, mainly in irrigated crops in semi-arid regions (Teixeira 2009).

According to Tanaka et al. (2008), estimation errors in energy balance components due to fetch problem or footprint discrepancy have been reduced with the advances in diagnostic procedures and technology. The measurements are usually done at one location that must be sufficiently downwind of any significant changes in the surface characteristics to allow development of the internal boundary layer to a depth greater than the top measurement height and to smooth out the effect of local surface heterogeneity. More essential sources of error might be the large-scale atmosphere mixing due to the night-time flux drainage and the daytime turbulent organized structure, although nighttime drainage being less important because of the small input of $R_{\mathrm{n}}$. During the night, as the air temperature and vapour pressure gradients are small, it is expected that larger errors occur when using BR systems than for daytime periods.

Alternative ways to force the energy balance closure in EC measurements have been studied in this paper with additional measurements of $R_{\mathrm{n}}$ and $G$ : the residual (RES); the combination (EC_BR); and the regression (REG) methods. In the case of RES method, $\lambda E$ is obtained as a residual in the energy balance equation after measuring directly $H$ (Simmons et al. 2007; Castellvi et al. 2008). The advantage of the RES method is that $\lambda E_{\text {RES }}$ can be obtained without expensive instrumentation for water vapour measurements, such as the application of the surface renewal method (Castellvi et al. 2008). By using the EC_BR method, after the EC measurements of $\lambda E$ and $H$, the first energy flux is recomputed by the Bowen ratio of the fluxes (Twine et al. 2000; Chehbouni et al. 2006). The REG method-to our knowledge first introduced by Allen (2008) - is based on a regression equation between $R_{\mathrm{n}}$ and the other energy balance terms providing weighting for each energy balance component.

One EC and one BR systems were set up to measure the energy fluxes in a micro-sprinkler-irrigated mango orchard in the Brazilian North-east. Growing of irrigated fruit crops in the semi-arid conditions of this region is important for the livelihoods of rural communities where water resources are strained. This paper compares five different energy balance interpretation and measurements, and the overall accuracy of the measured and estimated ET fluxes is investigated for different rainfall conditions. The performances of EC and BR techniques are evaluated, and the reasons for the lack of energy balance closure in the EC system and adjustments are discussed. The effects of forcing the latent and sensible heat fluxes from the EC system to match the available energy are examined. It is demonstrated that ET fluxes from the different methods and measurements are associated with considerable uncertainty.

\section{Materials and methods}

Measurement site and orchard conditions

A field measurement campaign was carried out from 2003 to 2005 in a mango orchard located in the semi-arid region of the Pernambuco State, Brazil, in Petrolina city $\left(09^{\circ} 22^{\prime} \mathrm{S}\right.$, $\left.40^{\circ} 34^{\prime} \mathrm{W}\right)$. The area at $370 \mathrm{~m}$ above the sea level has an average value for the total annual precipitation $(P)$ and pan evaporation of 570 and $2,700 \mathrm{~mm}$, respectively, at a mean air temperature $\left(T_{\mathrm{a}}\right)$ of $26.5^{\circ} \mathrm{C}$. The warmest month is November (average $T_{\mathrm{a}}$ of $28.2^{\circ} \mathrm{C}$ ) when the sun is in the zenith position at low cloud cover conditions. The coldest month is July (average $T_{\mathrm{a}}$ of $24.2^{\circ} \mathrm{C}$ ) at winter solstice in the southern hemisphere. Despite the relatively small thermal annual amplitude, due to the proximity of the equator, the increase in $T_{\mathrm{a}}$ together with higher levels of global solar radiation $\left(R_{\mathrm{G}}\right)$ during the hottest periods of the year affects crop ET. The annual thermal homogeneity strongly contrasts with the spatial and temporal heterogeneity of the rainfall regime. The rainy period is concentrated from January to April, representing 68\% of the annual amount, with water deficits in the climatic water balance along the year (Teixeira 2009).

The mango cultivar is Tommy Atkins, 18 years old in 2003 , with the trees spaced in a regular square pattern of $10 \mathrm{~m} \times 10 \mathrm{~m}$. The trees presented an average height of $5.5 \mathrm{~m}$, a mean leaf area index (LAI) of 5.6 and were pruned to a pyramidal and erect canopy, over an area of 11.92 ha bordered on all sides by other mango crops with similar height that matches fetch requirements. The mango trees undergone vegetative growth between November and January, followed by branch maturation from January to May, flowering from May to July, with fruit initiation between June and July. Fruit growth occurred from July to August, maturing during August and September being harvested between September and October. The sandy soil is classified as Latossoil Red-Yellow with low water 
retention capacity, with the groundwater depth approximately $2.5 \mathrm{~m}$, and the farm is located 5,500 $\mathrm{m}$ away from the banks of the São Francisco River (Teixeira et al. 2008a).

The orchard was daily micro-sprinkler-irrigated with one in-line micro-sprinkler between two trees on the ground and a discharge rate of $44 \mathrm{l} \mathrm{h}^{-1}$, which wetted $70 \%$ of the soil surface. The irrigation water requirements were calculated based on reference evapotranspiration and crop coefficients yielding to seasonal totals of 675 and $1,195 \mathrm{~mm}$ (1.7 and $\left.3.2 \mathrm{~mm} \mathrm{~d}^{-1}\right)$ during the first and second growing seasons, respectively. The differences in water applications were due to different rainfall amounts for the growing seasons. The study comprised two growing seasons including the previous post-harvest stage. The duration of the first period was 390 days, from 01 October 2003 (Day 274) to 24 October 2004 (Day 298). The measurements continued into a second period of 370 days, from 25 November 2004 (Day 299) to 29 November 2005 (Day 302).

\section{Orchard energy balance}

The sensors were installed at the centre of the study plot. All energy balance components were measured. Both EC and BR systems were used simultaneously (Fig. 1).

The EC system used determines the sensible $\left(\mathrm{H}_{\mathrm{EC}}\right)$ and latent $\left(\lambda E_{\mathrm{EC}}\right)$ heat fluxes by a three-axis sonic anemometer (Model CSAT3, Campbell Scientific, Logan, UT, USA) and a krypton hygrometer (Model KH20, Campbell Scientific, Logan, UT, USA), respectively, both connected to a datalogger (model CR10X, Campbell Scientific, Logan, UT, USA). The EC sensors were installed at a height of $8.5 \mathrm{~m}$ from the ground above the crowns of a row of trees, with a horizontal separation of $0.15 \mathrm{~m}$ and a sampling frequency of $16 \mathrm{~Hz}$. The fluxes were computed for $30 \mathrm{~min}$ periods and later summed to give daily totals.

For the BR method, the gradients of air temperature and vapour pressure were calculated using wet and dry

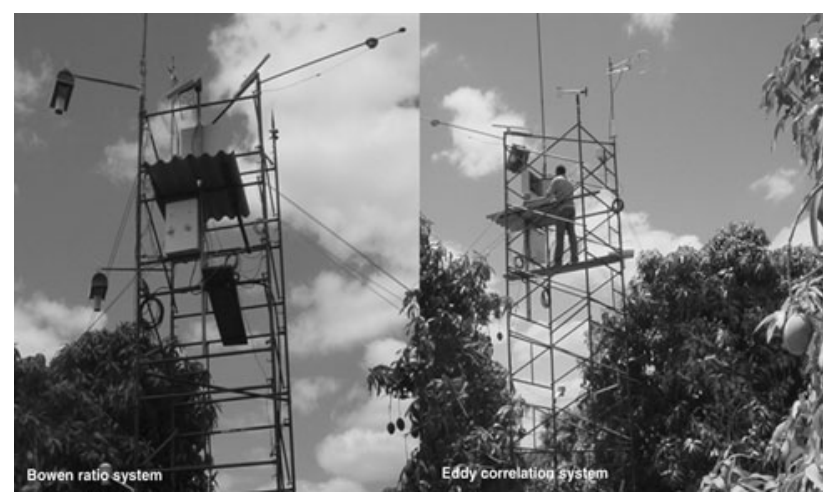

Fig. 1 Energy balance measurement systems in mango orchard, Petrolina-PE, Brazil thermocouples of copper/constantan at 1.0 and $3.0 \mathrm{~m}$ above the canopy positioned to the predominant south-west wind directions (Fig. 1). $R_{\mathrm{n}}$ was acquired with one net radiometer (model NR-Lite, Kipp \& Zonnen, Delft, The Netherlands) above a row of trees at a height of $7.5 \mathrm{~m}$. Previous experiments with fruit crops have shown that no big differences arise by using one sensor or two above and between rows for determination of $R_{\mathrm{n}}$ in row crops (Teixeira et al. 2007). $G$ was measured by two soil heat flux plates (model NR-Lite, Kipp \& Zonnen, Delft, The Netherlands) at $2 \mathrm{~cm}$ soil depth and below the projected tree crown at $100 \mathrm{~cm}$ from the trunk. The plates were buried at the west and east sides of a row of trees, and the values of $G$ were taken as the average of the two measurements, being not corrected for the heat storage above the plates. Heusinkveld et al. (2004) have shown that when the flux plates are close to the surface, corrections for heat storage are not necessary. Additional routine measurements of $R_{\mathrm{G}}$, $T_{\mathrm{a}}, P$, relative humidity (RH) and wind speed $(u)$ were also done over grass by an agro-meteorological station located $500 \mathrm{~m}$ from the orchard.

$R_{\mathrm{n}}, G$ and $T_{\mathrm{a}}$ in the experimental plot were measured at each 5-s interval, and averages of $10 \mathrm{~min}$ were stored in a datalogger (model CR10X, Campbell Scientific, Logan, UT, USA) equipped with a multiplexer (model AM416, Campbell Scientific, Logan, UT).

The energy fluxes can be expressed by the simplified energy balance equation:

$R_{\mathrm{n}}-\lambda E-G-H=0$

where all terms of Eq. 1 can be in $\mathrm{W} \mathrm{m}^{-2}$ or $\mathrm{MJ} \mathrm{m}^{-2} \mathrm{~d}^{-1}$ being either positive or negative. Positive $R_{\mathrm{n}}$ means energy flux to the surface and positive $G, \lambda E$ and $H$ indicate fluxes of energy from the surface.

Using data from the EC system, the latent $\left(\lambda E_{\mathrm{EC}}\right)$ and sensible $\left(\mathrm{H}_{\mathrm{EC}}\right)$ heat fluxes were calculated, respectively, by the following equations:

$\lambda E_{\mathrm{EC}}=\lambda \overline{w^{\prime} \rho_{\mathrm{v}}^{\prime}}$

$H_{\mathrm{EC}}=\rho_{\mathrm{a}} c_{\mathrm{p}} \overline{w^{\prime} T_{\mathrm{a}}^{\prime}}$

where $\lambda E_{\mathrm{EC}}$ and $H_{\mathrm{EC}}$ are in $\mathrm{W} \mathrm{m}{ }^{-2}, \lambda$ is the vaporization latent heat $\left(\mathrm{J} \mathrm{kg}^{-1}\right), w^{\prime}$ is the instantaneous deviation of vertical wind speed in relation to mean value $\left(\mathrm{m} \mathrm{s}^{-1}\right), \rho_{\mathrm{v}}{ }^{\prime}$ is the instantaneous deviation of water vapour density in relation to the mean value $\left(\mathrm{kg} \mathrm{m}^{-3}\right), \rho_{\mathrm{a}}$ is the air density $\left(\mathrm{kg} \mathrm{m}^{-3}\right), c_{\mathrm{p}}$ is the air specific heat at constant pressure ( $\mathrm{J} \mathrm{kg}^{-1} \mathrm{~K}^{-1}$ ) and $T_{\mathrm{a}}{ }^{\prime}$ is the instantaneous deviation of air temperature in relation to mean value $\left({ }^{\circ} \mathrm{C}\right)$. The quantities $\overline{w^{\prime} T_{\mathrm{a}}^{\prime}}$ and $\overline{w^{\prime} \rho_{v}^{\prime}}$ are the covariances between the vertical wind speed and air temperature and the vertical wind speed and water vapour density, respectively. The bars indicate averages (Stull 1998). 
A number of corrections to EC data have been proposed in literature. For this research, the ECPack from Wageningen University was applied (van Dijk et al. 2004a, b), which includes the following corrections:

1. Coordinate rotation of the $3 \mathrm{D}$ sonic wind speed vectors. Covariance is rotated to a natural coordinate system to partially consider the assumption that the measurements represent the flux perpendicular to the surface out of a nominal control volume defined at its top by the sensor and neglecting horizontal divergence so that the system becomes one-dimensional. The planar fit method is applied by the software (Wilczak et al. 2001).

2. Corrections due to density variations introduced by fluctuations of temperature and moisture content of air in updrafts and downdrafts which create spurious fluxes when air is measured volumetrically (Webb et al. 1980).

3. Oxygen absorption. Krypton hygrometers are used to measure the water vapour content of the air by absorption of $\mathrm{H}_{2} \mathrm{O}$ molecules in the ultraviolet spectrum. Due to the used wave length, there is a crosssensitivity to $\mathrm{O}_{2}$ molecules, which is corrected (Tanner et al. 1993).

4. Frequency losses. The turbulent flux density can be measured using eddy correlation, provided that fluctuations in the frequency range in which turbulent transport takes place are all sensed. In practice, this condition is hardly met due to a limited frequency response of the sensors and the data acquisition system; averaging over a path rather than taking a point value; separation between sensors for different quantities; and filtering applied. For each of these effects, a theoretical co-spectral transfer function is computed (Moore 1986).

The latent heat flux according to the BR method $\left(\lambda E_{\mathrm{BR}}\right)$ was calculated as follows:

$\lambda E_{\mathrm{BR}}=\frac{R_{\mathrm{n}}-G}{1+\beta}$

The related sensible heat flux in the BR method $\left(H_{\mathrm{BR}}\right)$ was computed as:

$H_{\mathrm{BR}}=\frac{R_{\mathrm{n}}-G}{1+1 / \beta}$

where $\lambda E_{\mathrm{BR}}, H_{\mathrm{BR}}, R_{\mathrm{n}}$ and $G$ are in $\mathrm{W} \mathrm{m}^{-2}$, and assuming that the eddy diffusivities for heat $\left(K_{\mathrm{H}}\right)$ and water vapour $\left(K_{\mathrm{v}}\right)$ are equal, $\beta$, the Bowen ratio, can be expressed as:

$\beta=\gamma\left(\frac{\Delta T}{\Delta e}\right)$

and $\gamma$ is the psychometric constant $\left(\mathrm{kPa}{ }^{\circ} \mathrm{C}^{-1}\right), \Delta T\left({ }^{\circ} \mathrm{C}\right)$ the vertical temperature gradient measured by the dry thermocouples and $\Delta e(\mathrm{kPa})$ is the vertical water vapour pressure gradient measured by the difference between dry and wet thermocouples over the height interval above the canopy surface.

In addition to these 'standard' measurements, two forcing energy balance closure methods were employed to estimate the latent heat flux from EC data: the residual $\left(\lambda E_{\mathrm{RES}}\right)$ and the combination $\left(\lambda E_{\mathrm{EC} \_\mathrm{BR}}\right)$ methods:

$\lambda E_{\mathrm{RES}}=R_{\mathrm{n}}-H_{\mathrm{EC}}-G$

$\lambda E_{\mathrm{EC} \_\mathrm{BR}}=\frac{R_{\mathrm{n}}-G}{1+\beta_{\mathrm{EC}}} ; \quad \beta_{\mathrm{EC}}=\frac{H_{\mathrm{EC}}}{\lambda E_{\mathrm{EC}}}$

where all energy fluxes are in $\mathrm{W} \mathrm{m}^{-2}$.

The daily actual evapotranspiration $\mathrm{ET}_{24}\left(\mathrm{~mm} \mathrm{~d}^{-1}\right)$ was obtained from the 24-h average latent heat flux $\lambda E_{24}$ $\left(\mathrm{W} \mathrm{m}{ }^{-2}\right)$, the latent heat of vaporization $\lambda\left(\mathrm{J} \mathrm{kg}^{-1}\right)$ and the density of water $\rho_{\mathrm{w}}\left(\mathrm{kg} \mathrm{m}^{-3}\right)$, throughout the different methods:

$\mathrm{ET}_{24}=8.64 \times 10^{7} \frac{\lambda E_{24}}{\lambda \rho_{w}}$

Quality control for the energy balance data

The deviation of BR, RES and EC_BR results from direct EC measurements can be ascribed to inaccuracies in $R_{\mathrm{n}}$ and $G$ data. In irrigated areas under semi-arid conditions, $R_{\mathrm{n}}$ is most likely to be accurate. $G$ measurements can affect considerably the energy balance for short timescale but do not influence $\lambda E$ values in direct EC measurements.

Missing EC-based $\lambda E$ data from the krypton hygrometer and missing BR-based $\lambda E$ data from instrumental problems and small temperature gradients during the rainy periods were filled by the relationship between $\left(H_{\mathrm{EC}}+\lambda E_{\mathrm{EC}}\right)$ and the available energy $\left(R_{\mathrm{n}}+G\right)$ for the lack of $\lambda E_{\mathrm{EC}}$ measurements and by the relation of $\lambda E_{\mathrm{BR}}$ with $\left(R_{\mathrm{n}}+G\right)$ to fill $\lambda E_{\mathrm{BR}}$ data gaps (Teixeira et al. 2008a). Footprint models were not necessary because the energy fluxes at $8.5 \mathrm{~m}$ elevation were surrounded by more than $850 \mathrm{~m}$ of homogenously irrigated mango plantations in all directions (i.e. 1:100 rule applies), as the plot of 11.92 ha was in the centre of a big commercial farm with 140 ha of mango orchards and with a predominant south-east wind direction, there was an upwind fetch of about $1.5 \mathrm{~km}$. After gap filling, the complete energy balances for the entire growing seasons could be derived.

Many research tried to explain and solve the problem of the lack of energy balance closure in EC systems. Wilson et al. (2002) summarized results from 22 flux sites of measurements and indicated a general lack at most of the sites, with a mean imbalance of about $20 \%$. This problem was also reported by Twine et al. (2000), Paço et al. (2006) and Testi et al. (2006), which can be associated with inaccurate measurements of $R_{\mathrm{n}}$ and $G$, but not completely 
explained by these inaccuracies, because EC systems have their own sources of error (Twine et al. 2000). Following Allen (2008), the lack of the closure in EC data can be solved by using a simple regression method that accounts for all sources of errors, assuming that $R_{\mathrm{n}}$ is the most accurate energy balance component in the semi-arid conditions. This approach does not favour one particular method and contains less assumptions; it just creates a correction on the basis of the best fit of independently collected field data:

$R_{n}=c_{0}+c_{1} G+c_{2} \lambda E_{\mathrm{EC}}+c_{3} H_{\mathrm{EC}}$

Equation 10 (all components in $\mathrm{W} \mathrm{m}^{-2}$ ) was applied to half-hour EC data with specific coefficients for daytimes and night-times, being an attractive solution based on the best statistical agreements of all fluxes, which ensures the energy balance closure providing unequal weighting of different measurements, depending on the variable uncertainty of each energy flux term.

\section{Results and discussion}

Weather conditions

Figure 2 shows the daily averaged weather variables during the two growing seasons of the mango orchard studied. The routine data collected by an automatic agro-meteorological station include $R_{\mathrm{G}}, T_{\mathrm{a}}$ and relative humidity $(\mathrm{RH})$, and wind speed $(u)$ above an irrigated grass surface for the reference evapotranspiration $\left(\mathrm{ET}_{0}\right)$ calculations.
The first growing season-GS1-with an average $R_{\mathrm{G}}$ of $21.8 \mathrm{MJ} \mathrm{m}^{-2} \mathrm{~d}^{-1}$, presented higher atmospheric demand than the second one-GS2 $\left(20.2 \mathrm{MJ} \mathrm{m}^{-2} \mathrm{~d}^{-1}\right)$. Although GS1 was wetter than GS2, $R_{\mathrm{G}}$ was larger outside the rainy period for the first growing season than for the second.

The mean $24 \mathrm{~h} T_{\mathrm{a}}$ reached its maximum value from October to December at approximately $29.5^{\circ} \mathrm{C}$. Minimum values occurred during June-July (around $22.5^{\circ} \mathrm{C}$ ). The values for vapour pressure deficit $(D)$ calculated for each half hour, and averaged for $24 \mathrm{~h}$, presented the same temporal behaviour as $T_{\mathrm{a}}$ throughout the growing seasons.

Average values of $u$ at $3 \mathrm{~m}$ above the grass field at the agro-meteorological station were highest from July to November (around $3.6 \mathrm{~m} \mathrm{~s}^{-1}$ ) and lowest from January to April (around $0.8 \mathrm{~m} \mathrm{~s}^{-1}$ ) for both growing seasons. The $\mathrm{u}$ values from the sonic anemometer over the mango orchard were $12 \%$ greater than over grass due to the aerodynamic properties of the tall mango trees.

Precipitation in the region is concentrated in the period from January to April with a long-term annual value of $570 \mathrm{~mm}$. The year 2004 was, however, unusually wet. The accumulated rainfall from October 2003 to October 2004 was $887 \mathrm{~mm}$, while from November 2004 to November 2005 , it was only $380 \mathrm{~mm}$.

\section{Energy balance closure}

The closure of the EC system measurements was analysed for the two growing seasons of the mango orchard at a daily timescale (Fig. 3). At this timescale analyses, the errors in $G$ measurements due to the variation in soil
Fig. 2 Daily values of weather variables during the study period 2003 to 2005: a global solar radiation $-R_{\mathrm{G}}$, b mean air temperature- $T_{\mathrm{a}}$; $\mathbf{c}$ water vapour pressure $-D, \mathbf{d}$ wind speed- $u$
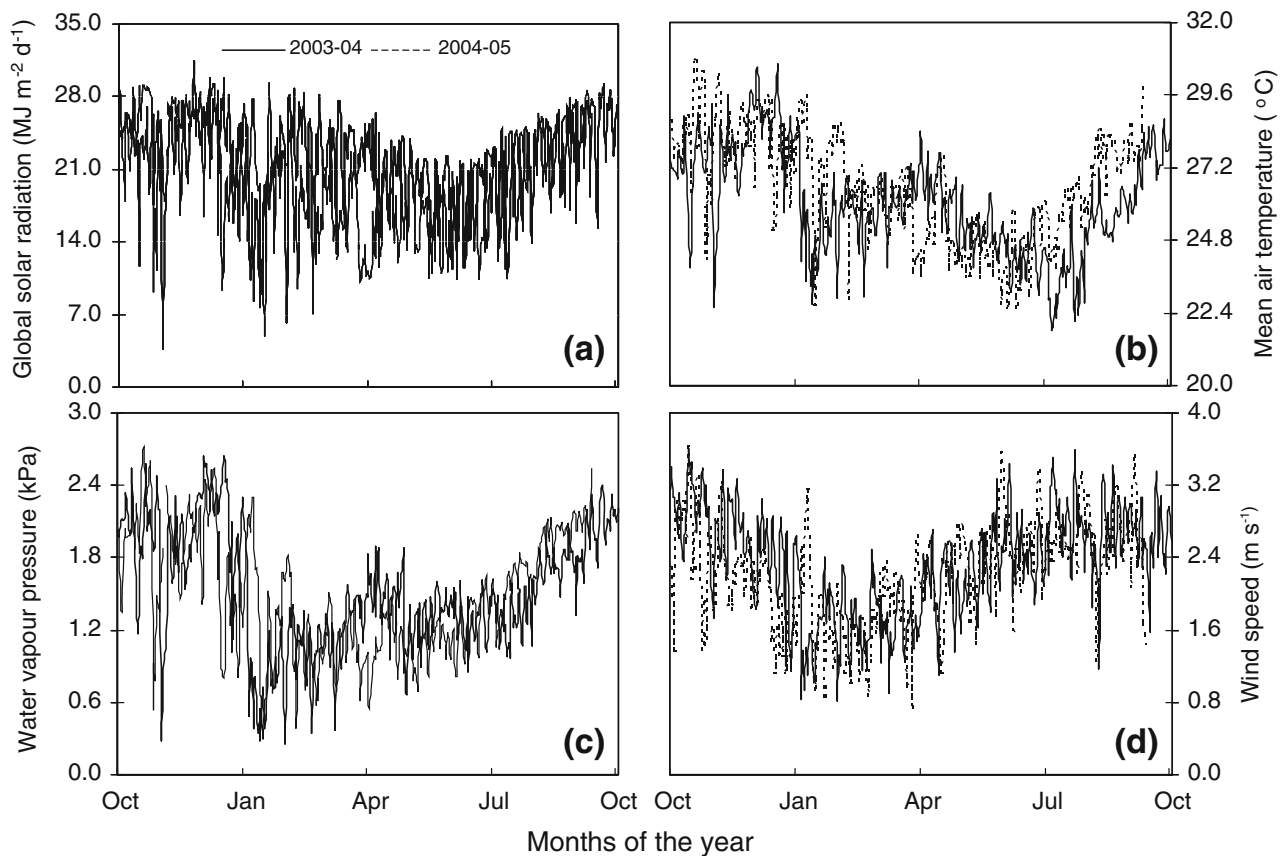
Fig. 3 Relationship between latent $\left(\lambda E_{\mathrm{EC}}\right)$ plus sensible $\left(H_{\mathrm{EC}}\right)$ heat fluxes from the eddy correlation system and the available energy $\left(R_{\mathrm{n}}-G\right)$ at daily timescales $(24 \mathrm{~h})$ : first growing season (2003-2004); second growing season (2004-2005)

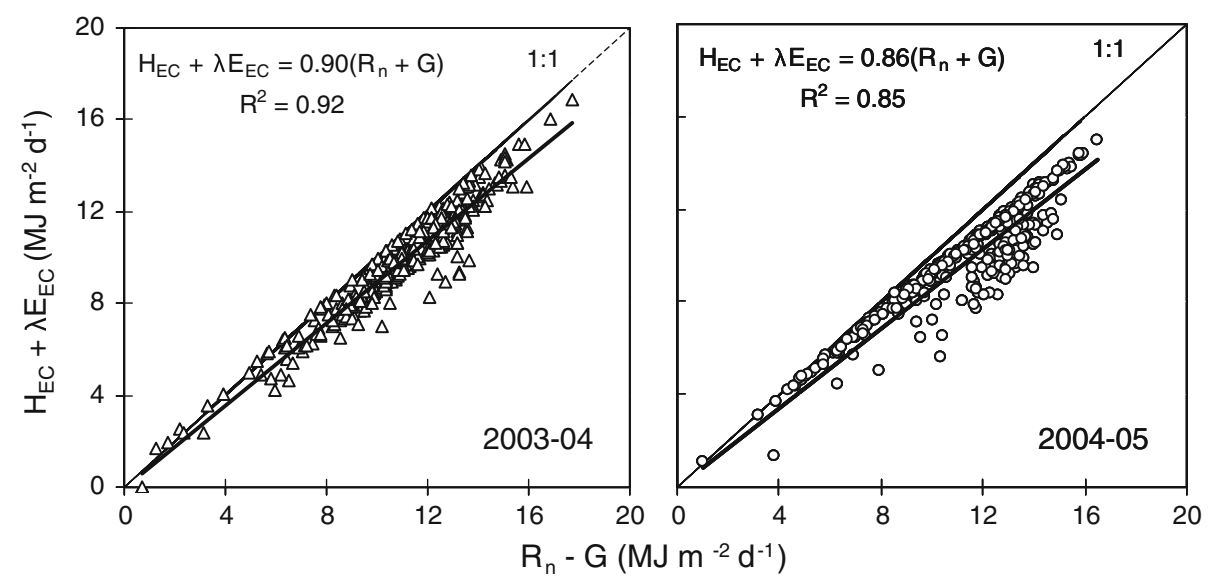

moisture and shadows of the canopy are reduced. The ratio of turbulent energy fluxes to the available energy was $88 \%$ on average, with a root mean square error (RMSE) of $1.7 \mathrm{MJ} \mathrm{m}^{-2} \mathrm{~d}^{-1}$, which is close to the lower limit of the range of $10-30 \%$ commonly found in the literature. As a first guess, either $H_{\mathrm{EC}}$ or $\lambda E_{\mathrm{EC}}$ (or a combination of them) could not be so reliable, because the EC measurements reflect errors from the system itself, mainly caused by rain; however, uncertainties also arise on $R_{\mathrm{n}}$ and $G$ measurements. Another aspect is that the energy storage in the canopies was not accounted in the available energy, which can be a source of error in mango tress which present large amount of branches and leaves. Depending on the time scales, the positive and negative values during days and nights of the energy fluxes can also influence these errors, making it important to analyse the effect of different methods of measurements and interpretation on these variations.

\section{Comparison of methods and data quality}

The sensible heat fluxes as obtained from the EC measurements and BR method were firstly compared. The relation for half-hour values involving all periods of the day during the two growing seasons of the mango orchard is shown in Fig. 4. The agreement was moderately good for both seasons, with general lower values for the BR method, but a considerable scatter is noticed. Lower scatter was observed in Fig. 3, and as a first guess, it is therefore likely that the BR measurements could be less reliable.

Considering both growing seasons, half-hour $H_{\mathrm{EC}}$ values were $25 \%$ higher than those for $H_{\mathrm{BR}}$. An underestimation of $H_{\mathrm{BR}}$ could be ascribed to inaccuracies in $R_{\mathrm{n}}$ and/or $G$ measurements, however, as the sonic anemometer is also not free of errors; an overmeasurement of $H_{\mathrm{EC}}$ could also be possible, mainly in conditions of high wind speed which by advection brings the hotter air from the dry areas at the vicinities of the mango orchards. On the other hand, the closure ratio, being 0.88 on average, can suggest that $H_{\mathrm{EC}}$ could be higher to meet the available energy, which reinforces a possible systematic underestimation in $H_{\mathrm{BR}}$ values, mainly for the first growing season due to more dense cloud cover and rainfall inducing lower temperature gradients. For the drier second growing season, it is evident that the scatter of the sensible heat fluxes from EC and BR systems' relation is larger for the higher values, which
Fig. 4 Comparison between the values of sensible heat fluxes obtained by the eddy correlation system $\left(H_{\mathrm{EC}}\right)$ and those from the Bowen ratio method $(B R)$ : first growing season (2003-2004); second growing season (2004-2005)

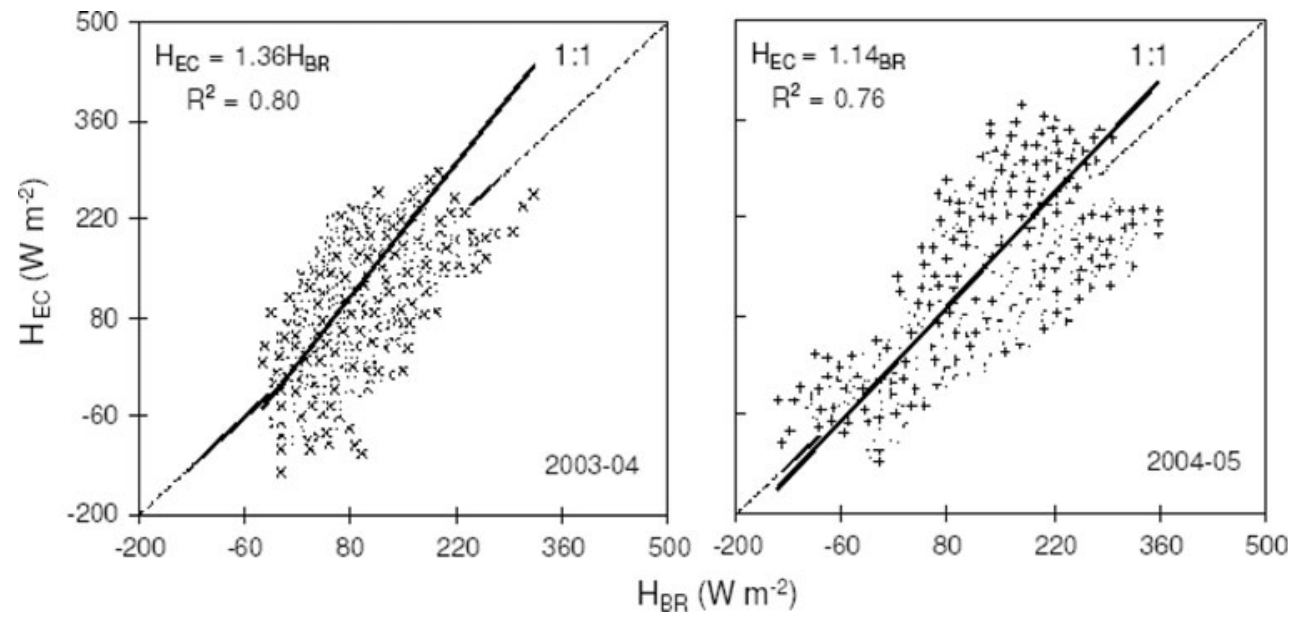


occur during daytime periods. As different errors exist according to the time of the day, the diurnal behaviour was also analysed. Figure 5 shows the variation of $H_{\mathrm{EC}}$ and $H_{\mathrm{BR}}$ during different times of the day; half-hour averaged values over the first and the second growing seasons of the mango orchard were used.

Figure 5 confirms the highest differences between the two systems around midday. The accuracy of BR method increases with more developed gradients $\Delta T$ and $\Delta e$, which occurred during the drier and hotter conditions. During rainfall periods, $\Delta T$ is difficult to measure and $\beta$ becomes more uncertain. While for the second growing season, the values of $H_{\mathrm{BR}}$ represented $73 \%$ of $H_{\mathrm{EC}}$, in the first one, $H_{\mathrm{BR}}$ accounted for $63 \%$ of $H_{\mathrm{EC}}$. The lower differences between methods occur between 07.00 and $09.00 \mathrm{~h}$ in the morning and $15.00-17.00 \mathrm{~h}$ in the afternoon, situations when the surface is, respectively, receiving and releasing solar energy. One reason for the less negative $H_{\mathrm{BR}}$ values during the night could be situations of $K_{\mathrm{h}}>K_{\mathrm{v}}$ for stable and advective conditions, making the assumption of similarity between these coefficients to deviate (Verma et al. 1978).

Figure 6 shows that the agreement of latent heat fluxes between EC measurements and BR method was more satisfactory than for sensible heat fluxes, even with an EC undermeasurement of $20 \%$ in relation to BR method. The $\mathrm{BR}$ values were higher than those for EC measurements due to the complementary relationship between $H_{\mathrm{BR}}$ and $\lambda E_{\mathrm{BR}}$, with the correlation between the two techniques $\left(R^{2}=0.95\right)$ being substantially higher than for the sensible heat flux $\left(R^{2}=0.78\right)$. Since both $\lambda E_{\mathrm{BR}}$ and $H_{\mathrm{BR}}$ are based on $\beta$ that close the energy balance, there is the possibility that $H_{\mathrm{EC}}$ could be overmeasured and $\lambda E_{\mathrm{EC}}$ undermeasured. The high correlation between $\lambda E_{\mathrm{BR}}$ and $\lambda E_{\mathrm{EC}}$ suggests, however, that $\lambda E_{\mathrm{EC}}$ is less wrong than $H_{\mathrm{EC}}$, and it could possibly pinpoint that $H_{\mathrm{EC}}$ is one of the uncertain parameters. As for the sensible heat fluxes, different errors in the $\mathrm{EC}$ and BR systems for the latent heat flux measurements arise according to the time of the day, being evidenced by the largest distances from the line 1:1 for the higher values of the relation depicted in Fig. 6.

The diurnal behaviours of $\lambda E_{\mathrm{EC}}$ and $\lambda E_{\mathrm{BR}}$ are shown in Fig. 7. Half-hour averaged values over the first and the second growing seasons of the mango orchard were used. It is confirmed that $\lambda E_{\mathrm{EC}}$ values agree very well with $\lambda E_{\mathrm{BR}}$ values and that the largest differences occur during midday, when $\lambda E_{\mathrm{BR}}$ is $35 \%$ greater than $\lambda E_{\mathrm{EC}}$. As the temperature and vapour pressure gradients used for $\beta$ calculations (see Eq. 6) are most strongly developed during noon, this is somewhat unexpected as this parameter can be measured with more accuracy than during the early morning or late afternoon. An overestimation of $\lambda E_{\mathrm{BR}}$ at noon could be in part a consequence of advective effects at this time of the day under well-irrigated conditions in a semi-arid region. As for the sensible heat fluxes, the lowest differences occurred between 07.00 and $09.00 \mathrm{~h}$ in the morning and $15.00-17.00 \mathrm{~h}$ in the afternoon. $\lambda E_{\mathrm{BR}}$ was 24 and $22 \%$ higher than $\lambda E_{\mathrm{EC}}$, respectively, for the first and second growing seasons. Seasonal differences are mainly due to the fact that in the BR method, the closure of the energy balance is forced in addition to the assumption of the similarity between sensible and latent heat turbulent diffusion coefficients in the energy balance equations.

Dugas et al. (1991) comparing four BR systems and three EC systems in an irrigated wheat field in Arizona (USA) founded $H_{\mathrm{EC}}$ values being 82 and $69 \%$ of $H_{\mathrm{BR}}$, during 2 days of measurements, respectively, while $\lambda E_{\mathrm{EC}}$ values were 77 and $67 \%$ of $\lambda E_{\mathrm{BR}}$. The differences in their latent heat flux measurements were comparable with our results for the irrigated mango orchard, although the inverse situation occurred for the sensible heat flux values, supporting a possible overestimation of our $H_{\mathrm{EC}}$ measurements.

In the case of using the RES method for forcing the energy balance closure, the sensible heat fluxes were acquired with the sonic anemometer together with additional measurements of $R_{\mathrm{n}}$ and $G$. $\lambda E_{\mathrm{RES}}$ was then obtained as a residual in the energy balance (see Eq. 7). Figure 8
Fig. 5 Diurnal trend for the sensible heat flux during the first (2003-2004) and the second (2004-2005) growing seasons for the mango orchard. Averaged half-hour values for the eddy correlation $(E C)$ and the Bowen ratio $(B R)$ systems were used

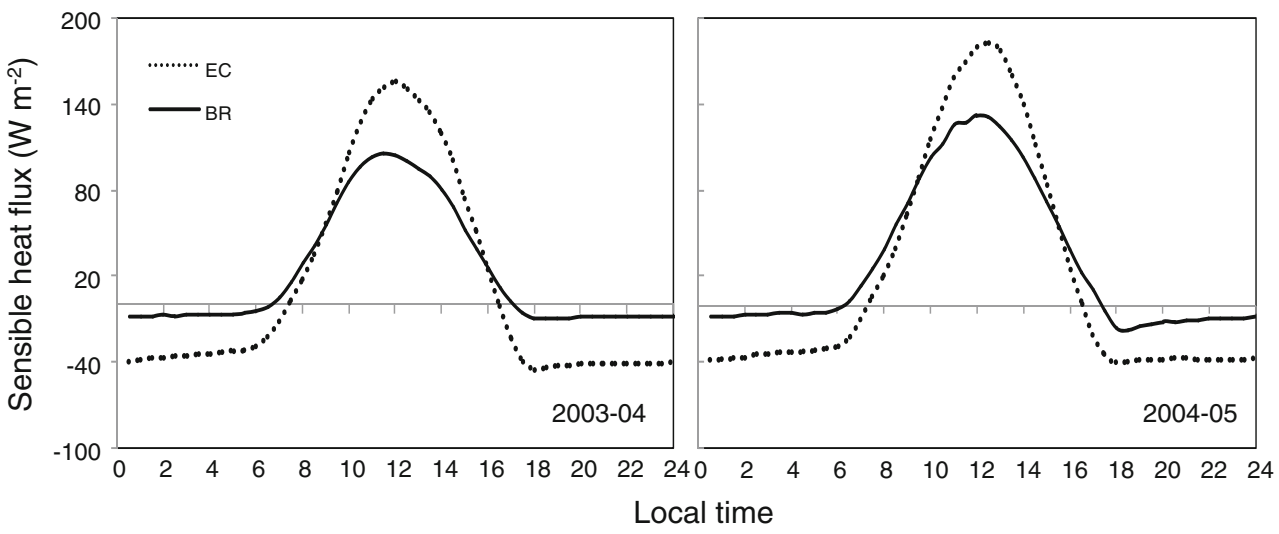


Fig. 6 Comparison between values of latent heat fluxes obtained by eddy correlation measurements $\left(\lambda E_{\mathrm{EC}}\right)$ with $\left(\lambda E_{\mathrm{BR}}\right)$ : first growing season (2003-2004); second growing season (2004-2005). Half hourly values are depicted those from Bowen ratio method

Fig. 7 Diurnal trend for the latent heat flux during the first (2003-2004) and the second (2004-2005) growing seasons for the mango orchard: Averaged half-hour values for the eddy correlation $(E C)$ and the Bowen ratio $(B R)$ measurements are depicted

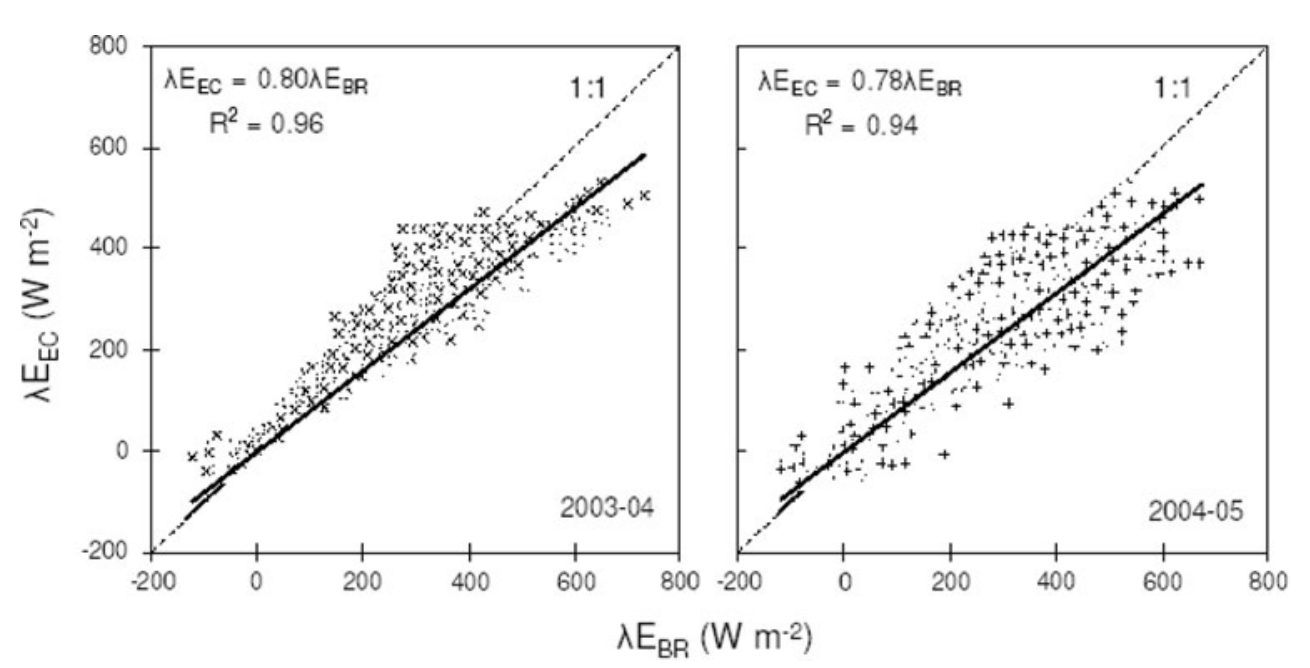

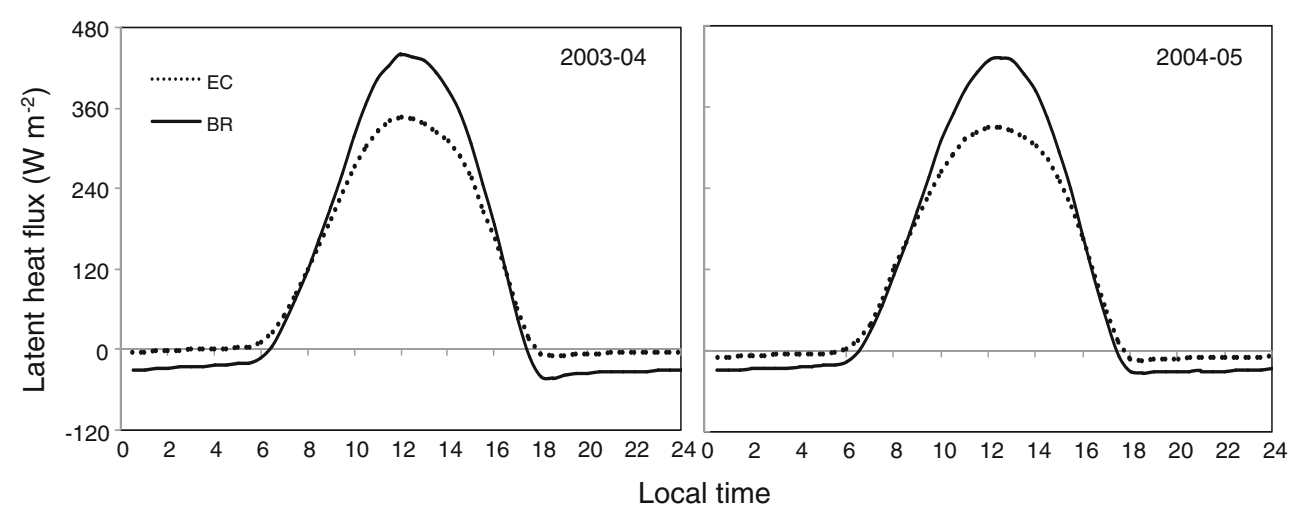

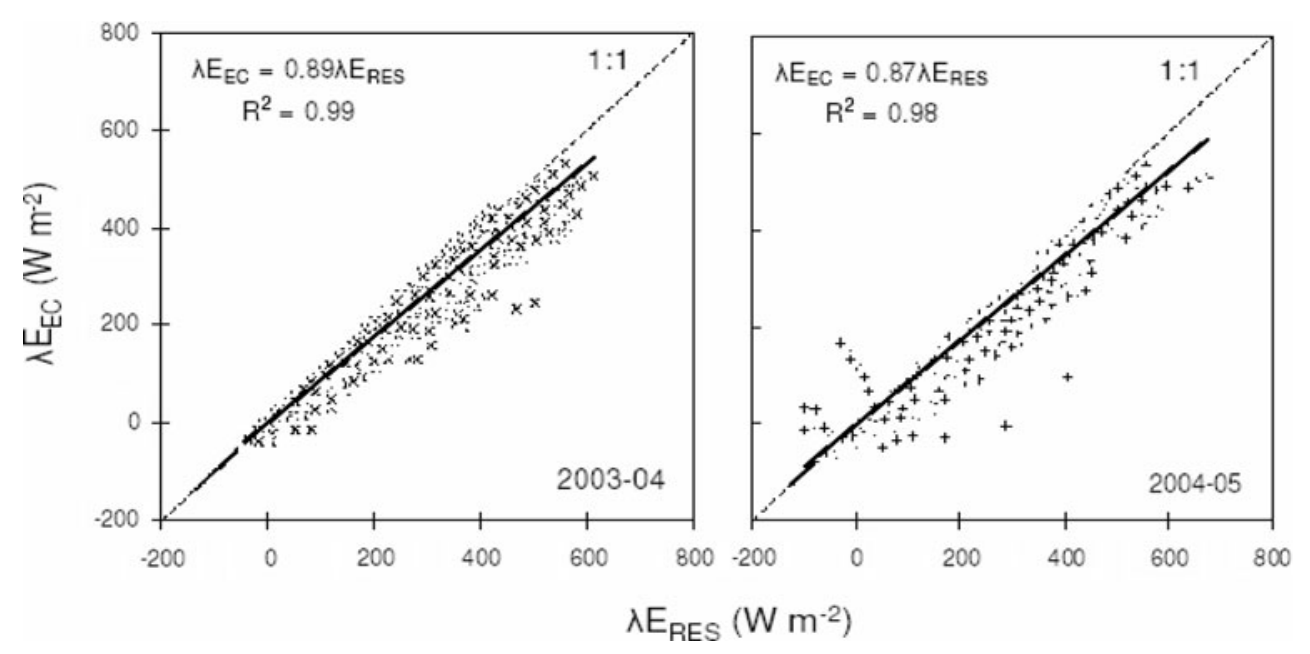

Fig. 8 Comparison between the values of latent heat fluxes obtained by the eddy correlation measurements $\left(\lambda E_{\mathrm{EC}}\right)$ with those from residual method $\left(\lambda E_{\mathrm{RES}}\right)$ : first growing season season (2004-2005). Half hourly values are depicted (2003-2004); second growing

shows the results of the relationship for $\lambda E_{\mathrm{EC}}$ and $\lambda E_{\mathrm{RES}}$ values taking half hour measurements, which presented lower scatter than for BR method. In agreement with the lack of the energy balance closure in the EC system, the $\lambda E_{\mathrm{EC}}$ represented around $88 \%$ of $\lambda E_{\mathrm{RES}}$ which could be an indication of an overestimation of $\lambda E_{\mathrm{RES}}$ or an undermeasurement of $\lambda E_{\mathrm{EC}}$. Whatever is right, this evidences the fact that both BR and RES methods, closing the energy balance, provide an uncertainty of more than $10 \%$ in the final ET measurements. Simmons et al. (2007), using EC measurements and the RES method over a flood-irrigated pecan orchard during two growing seasons in New Mexico, reported that for the daily values there was an undermeasurement of $\lambda E_{\mathrm{EC}}$ within $8 \%$ for both growing seasons. In their study, the method presented fewer problems in $G$ accuracy at short timescale, because if the surface is 
flooded, the spatial distribution of this energy balance component is more homogeneous.

Earlier and actual results for BR and RES methods are somewhat disappointing if these field values are to be used to validate soil water balance models or remote sensing algorithms. The uncertainties of $R_{\mathrm{n}}$ and $G$ are propagated into both methods. Even $G$ accounting only for $10-30 \%$ of $R_{\mathrm{n}}$, the hole of $G$ fluxes in the closure problem has been attempted for the surface energy balance in vegetated and not vegetated surfaces (Heilman et al. 1994; Heusinkveld et al. 2004). The advantage of using these methods is that $\lambda E_{\mathrm{BR}}$ and $\lambda E_{\mathrm{RES}}$ can be obtained without expensive instrumentation. An example of application of the RES method in a cheap way is by using the surface renewal method to measure the sensible heat flux (Castellvi et al. 2008).

The EC_BR combination approach applying the Eq. 8 was also compared with direct EC measurements. The method recomputes the latent heat fluxes from EC system by using the ratio $H_{\mathrm{EC}} / \lambda E_{\mathrm{EC}}$ and the measured available energy (Twine et al. 2000). Figure 9 shows the relation between the latent heat fluxes obtained by EC measurements and by the EC_BR method. The results of the $\lambda E_{\mathrm{EC} \_\mathrm{BR}}$ and $\lambda E_{\mathrm{RES}}$ are comparable. Chehbouni et al. (2006) also used this EC_BR method over irrigated wheat in the Yaqui Valley in Northwest Mexico. While the lack of energy balance closure could undermeasure $\lambda E_{\mathrm{EC}}$, it is believed that forcing the closure by this combination method (EC_BR), this undermeasurement should be corrected (e.g. Hoedjes et al. 2002). However, the EC_BR method again brings the uncertainties of $R_{\mathrm{n}}$ and $G$ as the BR and RES methods, being not necessarily better, unless independent water balance estimates confirm this. In addition, the advantages of direct measurements of EC systems are incorporated into this combination method.

The methods discussed before have uncertainties in all measurements, and no overriding argument can be found for favouring a certain solution. A final method was applied to solve the lack of energy balance closure in the EC system and to assess the data quality, by means of a curve fitting involving all energy balance components (Allen 2008). Equation 10 was applied to half-hour periods by using: (1) all data, (2) daytime data only and (3) night-time data only. Systematic corrections were identified for the two growing seasons of the mango orchard (Table 1).

The regression coefficients $\left(R^{2}\right)$ were highest for all data included, averaging 0.97 when used in association with an offset $c_{0}$, even though for night-time periods the $R^{2}$ being 0.65 for the second growing season. The high regression coefficients for all data included can be attributed to the large extremes and variations in the combined data set that strongly reduced the root mean square error (RMSE) in relation to the situations when only daytime or night-time data were used.

In both growing seasons, $H_{\mathrm{EC}}$ appeared to be undermeasured during the day and overmeasured during the night, which supports an underestimation of $H_{\mathrm{BR}}$ during daytime periods in Fig. 5. $\lambda E_{\mathrm{EC}}$ was overmeasured during the daytime periods, which supports an overestimation of $\lambda E_{\mathrm{BR}}$ in Fig. 7 for this time of the day. For the growing season of 2003-2004, the differences between the corrected and uncorrected values of latent and sensible heat fluxes were larger than those for the growing season of 2004-2005 as a result of the unusual rains during 2004 which affected both the sonic anemometer and the krypton hygrometer measurements. $G$ was highly undermeasured during all periods of the day, although the correction coefficients were much higher for daytime periods. This was expected as the soil heat plates were buried near the irrigation system, because they could not be installed between the rows due to the path of machines. The very low measured $G$ values are attributed to the high soil moisture levels near the micro-sprinklers and the shadowing effects of the mango trees during daytime periods promoting high thermal soil conductivity.

Taking all periods of the day and the average conditions for the two growing seasons, half-hourly $\lambda E_{\mathrm{EC}}$ was
Fig. 9 Comparison between the latent heat fluxes obtained by the eddy correlation measurements $\left(\lambda E_{\mathrm{EC}}\right)$ with those from the combination method $\left(\lambda E_{\mathrm{EC} \_\mathrm{BR}}\right)$ : first growing season-(2003-2004); second growing season (2004-2005). Half hourly values are depicted
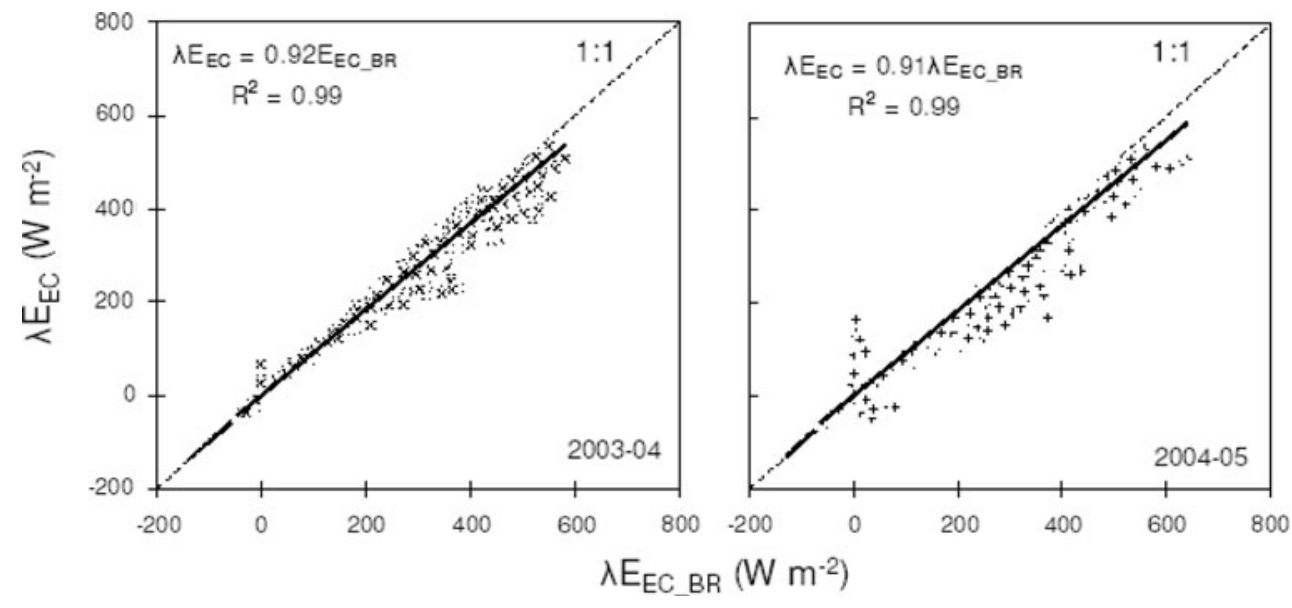
Table 1 Energy balance regression coefficients for 30-min energy balance measurements over mango orchard at Petrolina-PE, Brazil, during the growing seasons of 2003-2004 and 2004-2005

\begin{tabular}{llllllc}
\hline Data & $\begin{array}{l}c_{0} \\
\left.(\mathrm{~W} \mathrm{~m})^{-2}\right)\end{array}$ & $\begin{array}{l}c_{1} \\
(\mathrm{G})\end{array}$ & $\begin{array}{l}c_{2} \\
(\lambda E)\end{array}$ & $\begin{array}{l}c_{3} \\
(\mathrm{H})\end{array}$ & $R^{2}$ & $\begin{array}{l}\text { RMSE } \\
\left(\mathrm{W} \mathrm{m}^{-2}\right)\end{array}$ \\
\hline $2003-2004$ & & & & & & \\
All & - & 4.25 & 0.71 & 1.47 & 0.93 & 37.1 \\
Daytime & - & 5.01 & 0.64 & 1.48 & 0.86 & 53.6 \\
Night-time & - & 1.54 & 1.08 & 0.67 & 0.80 & 2.4 \\
All & 54.9 & 4.00 & 0.67 & 1.38 & 0.98 & 13.3 \\
Daytime & 76.9 & 6.54 & 0.54 & 1.25 & 0.90 & 69.4 \\
Night-time & -11.8 & 1.22 & 0.86 & 0.53 & 0.81 & 2.1 \\
2004-2005 & & & & & & \\
All & - & 5.06 & 0.93 & 0.87 & 0.93 & 25.2 \\
Daytime & - & 5.21 & 0.73 & 1.40 & 0.91 & 36.0 \\
Night-time & - & 1.54 & 0.88 & 0.58 & 0.46 & 4.8 \\
All & 40.2 & 4.80 & 0.88 & 0.82 & 0.96 & 14.9 \\
Daytime & 61.4 & 4.58 & 0.64 & 1.23 & 0.93 & 35.1 \\
Night-time & -17.4 & 1.05 & 0.60 & 0.40 & 0.65 & 3.7 \\
\hline
\end{tabular}

overmeasured by $18 \%, H_{\mathrm{EC}}$ was undermeasured by $17 \%$, and $G$ measurements required the biggest correction of $466 \%$. Although the intercept $c_{0}$ for daytime periods was large (average of $69 \mathrm{~W} \mathrm{~m}^{-2}$ ), a small improvement in $R^{2}$ was achieved with its use. The REG method was then applied to the energy balance components for the first and second growing seasons of the mango orchard at 30-min intervals with only the coefficients $c_{1}, c_{2}$ and $c_{3}$ from Table 1 for daytime and night-time separately.

As the biggest discrepancy was from $G$ values, an analysis for the diurnal behaviour of this energy balance component is provided by using half-hour averaged values over the first (2003-2004) and the second (2004-2005) growing seasons of mango orchard (Fig. 10). It can be seen from Fig. 10 and Table 1 that both $G$ values and corrections coefficients were lower for the rainier growing season than those for the drier one during the daytime periods. The reason is that the rain kept $G$ more homogeneous with a higher thermal conductivity during the first growing season. Considering all periods of the day and both growing seasons, the averaged correction coefficient of 4.66 is too high because of the absence of measurements between rows, showing the importance of the REG method for short timescales, which considers all energy balance components to force the closure in situations of difficult reliable $G$ measurements, as for sparse irrigated crops. The effect of the shadow of the trees is evident by the lower values around midday with midmorning and midafternoon peaks, mainly during the drier conditions of 2004-2005 (Heilman et al. 1994, 1996; Teixeira et al. 2007).

Despite the biggest correction for the half-hour $G$ values in relation to the other energy balance components, the effect of these measurement errors in the available energy ( $\left.\mathrm{AE}=R_{\mathrm{n}}-G\right)$ is low (Fig. 11). The small differences in $\mathrm{AE}$ are due to that $G$ accounted only for a small portion of $R_{\mathrm{n}}$ (Heusinkveld et al. 2004). When taking daily values, which are considered for irrigation management, $G$ tends to zero and the correction becomes irrelevant at this timescale. After applying the corrections for $G$, considering the coefficients for day- and night-times from Table 1 separately, the corrected values of $\mathrm{AE}$ represented $93 \%$ of the uncorrected ones. Hence, measurement errors in $G$ were not the main reason for the lack in the daily energy balance closure of the EC system.

Seasonal variations of the averaged daily values of net radiation and latent heat fluxes from the different measurements and methods used during the two growing seasons of the mango orchard are portrayed in Table 2.

Although the seasonal behaviour of $G$ is not shown in Table 2, the average values of the evaporative fractions $(\mathrm{EF}=\lambda E / \mathrm{AE})$ (Shuttleworth et al. 1989) ranged from 0.71 to 0.89 , among the measurements and methods. The differences in EF between the methods were more modest than those for $\lambda E$. The mean $\Delta E F$ was 0.17 for 2003-2004 and 0.14 for 2004-2005. The reason is the inclusion of AE in the definition of EF, which, according to the Fig. 11, presented small differences between the corrected and uncorrected values, mainly for periods of the day outside the noon time. During an earlier BR energy balance study
Fig. 10 Diurnal averages for measured $(G)$ and corrected $(G c)$ soil heat fluxes, during the first (2003-2004) and the second (2004-2005) growing seasons for the mango orchard. Averaged half hour values are depicted

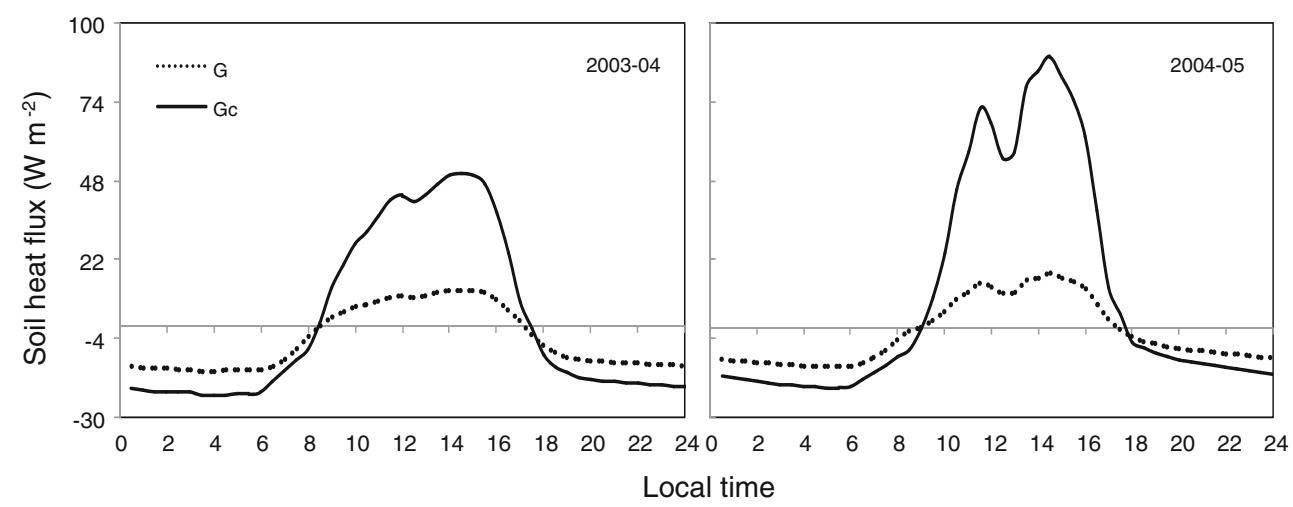


Fig. 11 Diurnal averages for the measured $(A E)$ and corrected $(A E c)$ available energy, during the first (2003-2004) and the second (2004-2005) growing seasons for the mango orchard. Averaged half hour values are depicted

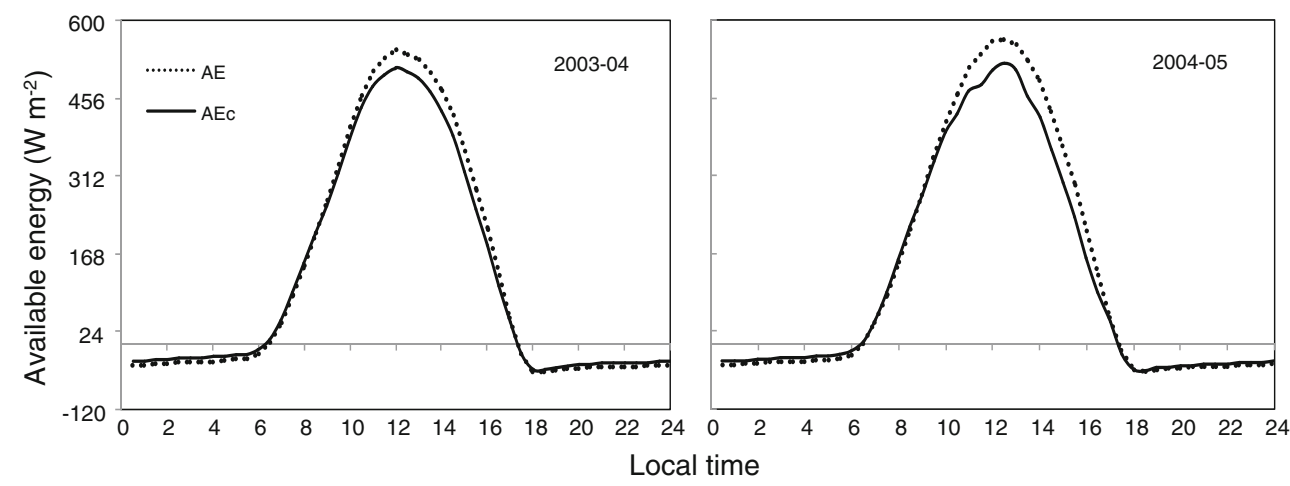

Table 2 Daily averages of net radiation $\left(R_{\mathrm{n}}\right)$ and latent heat fluxes $(\lambda E)$ in a mango orchard, using different measurements and methods

\begin{tabular}{|c|c|c|c|c|c|c|}
\hline Day/year & $R_{\mathrm{n}}\left(\mathrm{MJ} \mathrm{m}^{-2} \mathrm{~d}^{-1}\right)$ & $\lambda E_{\mathrm{EC}}\left(\mathrm{MJ} \mathrm{m}^{-2} \mathrm{~d}^{-1}\right)$ & $\lambda E_{\mathrm{BR}}\left(\mathrm{MJ} \mathrm{m}^{-2} \mathrm{~d}^{-1}\right)$ & $\lambda E_{\mathrm{RES}}\left(\mathrm{MJ} \mathrm{m}^{-2} \mathrm{~d}^{-1}\right)$ & $\lambda E_{\mathrm{EC} \_\mathrm{BR}}\left(\mathrm{MJ} \mathrm{m}^{-2} \mathrm{~d}^{-1}\right)$ & $\lambda E_{\mathrm{REG}}\left(\mathrm{MJ} \mathrm{m}^{-2} \mathrm{~d}^{-1}\right)$ \\
\hline \multicolumn{7}{|c|}{ 2003-2004 } \\
\hline $303 / 03$ & 9.66 & 7.55 & 7.86 & 8.92 & 8.43 & 5.20 \\
\hline $333 / 03$ & 10.84 & 8.36 & 8.96 & 9.86 & 9.49 & 5.90 \\
\hline $363 / 03$ & 10.64 & 8.19 & 8.75 & 9.66 & 9.13 & 5.66 \\
\hline $028 / 04$ & 9.73 & 8.00 & 8.37 & 8.36 & 8.30 & 5.87 \\
\hline 058/04 & 12.18 & 9.54 & 10.90 & 10.59 & 10.28 & 6.94 \\
\hline 088/04 & 11.69 & 8.92 & 10.09 & 10.09 & 10.15 & 6.47 \\
\hline $118 / 04$ & 11.96 & 9.83 & 10.32 & 10.63 & 10.46 & 7.06 \\
\hline $148 / 04$ & 9.75 & 8.07 & 8.33 & 8.59 & 8.45 & 5.75 \\
\hline $178 / 04$ & 8.91 & 7.51 & 7.57 & 8.48 & 8.09 & 5.34 \\
\hline $208 / 04$ & 8.70 & 7.42 & 6.83 & 8.21 & 8.01 & 5.24 \\
\hline $238 / 04$ & 9.71 & 7.97 & 8.26 & 8.88 & 8.49 & 5.63 \\
\hline $268 / 04$ & 11.51 & 10.12 & 9.79 & 11.83 & 11.19 & 7.08 \\
\hline $298 / 04$ & 12.21 & 10.30 & 10.14 & 12.73 & 11.65 & 7.23 \\
\hline Mean & 10.58 & 8.60 & 8.94 & 9.76 & 9.39 & 6.11 \\
\hline \multicolumn{7}{|c|}{ 2004-2005 } \\
\hline $327 / 04$ & 12.47 & 8.82 & 9.44 & 11.92 & 10.61 & 8.33 \\
\hline $354 / 04$ & 12.17 & 8.42 & 7.87 & 11.06 & 10.17 & 7.95 \\
\hline 016/05 & 11.67 & 7.76 & 8.11 & 9.41 & 8.71 & 7.31 \\
\hline $044 / 05$ & 12.13 & 8.73 & 9.20 & 9.78 & 9.37 & 8.18 \\
\hline $072 / 05$ & 11.87 & 8.49 & 9.15 & 9.60 & 9.10 & 7.94 \\
\hline $100 / 05$ & 12.41 & 8.74 & 10.04 & 9.88 & 9.43 & 8.18 \\
\hline $128 / 05$ & 9.04 & 7.36 & 7.28 & 8.08 & 8.11 & 6.89 \\
\hline $156 / 05$ & 8.78 & 7.29 & 7.15 & 7.96 & 7.85 & 6.83 \\
\hline $184 / 05$ & 8.43 & 7.16 & 7.11 & 7.79 & 7.67 & 6.71 \\
\hline $212 / 05$ & 10.03 & 7.85 & 7.61 & 9.23 & 8.40 & 7.30 \\
\hline $240 / 05$ & 10.62 & 7.93 & 8.34 & 8.94 & 8.56 & 7.45 \\
\hline $268 / 05$ & 12.04 & 8.45 & 9.74 & 9.58 & 9.14 & 7.94 \\
\hline
\end{tabular}

Data were collected during the growing seasons of 2003-2004 and 2004-2005

* The subscripts EC, BR, REG, RES and EC_BR mean the eddy correlation, Bowen ratio, regression, residual and the combination of EC and BR methods, respectively

in a mango orchard close to our study site, the EF values were found to be 0.73 in August, 0.86 in September, 0.78 in October and 0.80 during November (Lopes et al. 2001), being inside the range of our actual study.
Figure 12 presents the seasonal behaviour of EF for all methods from 2003 to 2005, involving the two growing seasons of the mango orchard. In general, the EF values remained fairly constant with a standard deviation between 
0.03 and 0.07 , which is ascribed to a daily micro-sprinkler irrigation water supply. The rainy season concentrates from January to April, and during this period, farmers stop irrigation, thus causing a drop in EF during the maturing phase of the crop growth. The EC measurements were more sensitive than the BR estimates to detect such effects. During the drier second growing season (after the Day/ Year 298/2004), the EF curve from the REG method in Fig. 12 became a good representation of the average EF values. It is also evident when comparing Figs. 2 and 12 that the lowest differences in energy partitioning between measurements and methods happened during the driest and coldest conditions of the second growing season (from Day/Year 120/2005 to 270/2005). Testi et al. (2004) studied the variation of EF in a young olive orchard under different water conditions and concluded that the values are influenced by soil moisture, which is also supported by Scott et al. (2003a, b) for irrigation systems in Mexico and Pakistan.

The accumulated ET for the five interpretation and measurements methods studied for the two growing seasons of the mango orchard is summarized in Fig. 13. It can

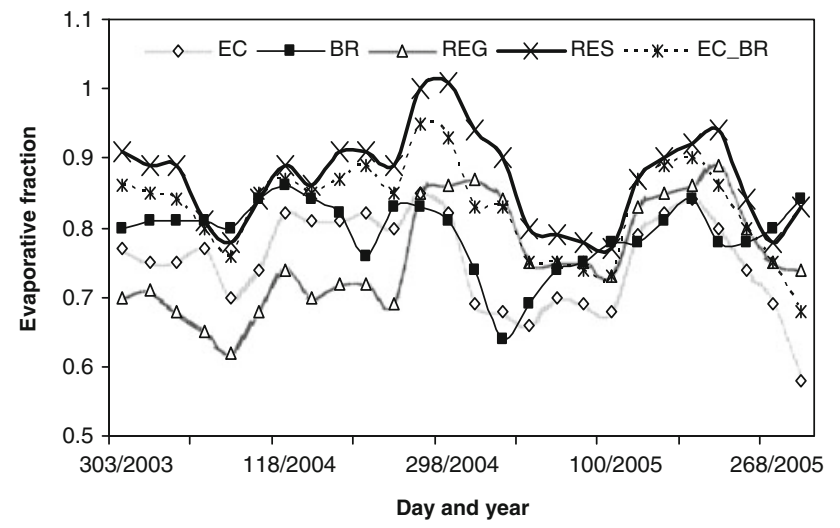

Fig. 12 Evaporative fraction $(E F)$ determined by eddy correlation $(E C)$ measurements; Bowen ratio $(B R)$, regression $(R E G)$, residual $(R E S)$ and the combination (EC_BR) methods be seen that the RES method produced the highest accumulated values in both growing seasons, followed by the EC_BR method, the BR method, the EC measurements and the REG method, with averages of $1,496 \mathrm{~mm}$ (RES), $1,419 \mathrm{~mm}$ (EC_BR), 1,362 mm (BR), 1,289 $\mathrm{mm}$ (EC) and $1,046 \mathrm{~mm}$ (REG), respectively, for the two growing seasons. The accumulated differences between methods and measurements increased progressively towards the harvest dates.

Table 3 shows the seasonal ET for the five methods and measurements considering the growing seasons of the mango orchard of 2003-2004 (wetter conditions) and 2004-2005 (drier conditions) together with the differences in percentages taking the REG method as a reference.

Considering the higher confidence in the results of the second growing season, it was taken as a reference to analyse the differences in ET obtained from EC measurements and the other methods over large time periods. The REG method is a good choice because it forces a closed energy balance; maximally utilizes highly advanced eddy correlation systems; does not exclude any flux measurement from the optimization process; and adds variable weights to the energy fluxes, which seems acceptable because actual deviations of the fluxes from reality are not known. With these considerations, it is concluded that seasonal ET values obtained by direct EC measurements in mango orchard are around $7 \%$ higher than those from the REG method (Table 3). Hence, we believe that $\lambda E_{\mathrm{EC}}$ is overestimating the true seasonal ET, despite that $\lambda E_{\mathrm{BR}}$, $\lambda E_{\mathrm{RES}}$ and $\lambda E_{\mathrm{EC} \_\mathrm{BR}}$ values were found to be even higher.

\section{Conclusions}

The energy balance components of a large commercial mango orchard were analysed at different timescales by applying five interpretation and correction methods. The basic measurements were from eddy correlation (EC) and
Fig. 13 Accumulated actual evapotranspiration of a mango orchard, at Petrolina $(P E)$, Brazil, during the growing seasons of 2003-2004 and 2004-2005: eddy correlation technique $(E C)$; Bowen ratio method $(B R)$; regression method $(R E G)$; residual method (RES); and the combination method $\left(E C \_B R\right)$

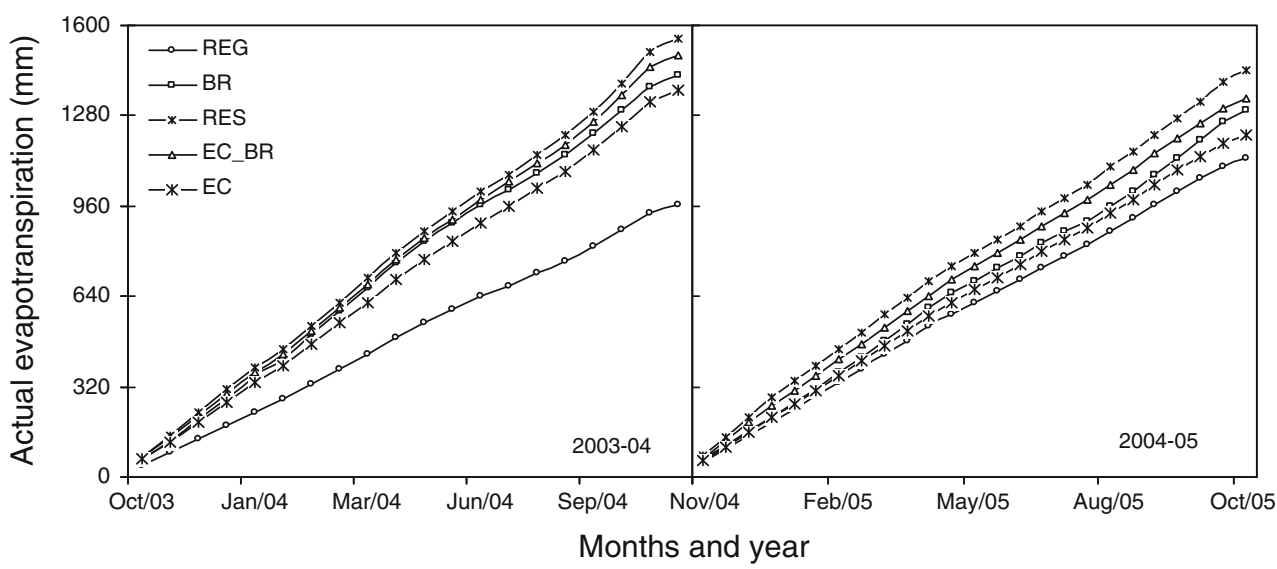


Table 3 Seasonal evapotranspiration (ET) of a mango orchard at Petrolina-PE, Brazil, interpreted from five methods and measurements during the growing seasons of 2003-2004 and 2004-2005

\begin{tabular}{llllll}
\hline $\begin{array}{l}\text { GS/ } \\
\text { method }\end{array}$ & $\mathrm{ET}_{\mathrm{EC}}$ & $\mathrm{ET}_{\mathrm{BR}}$ & $\mathrm{ET}_{\mathrm{REG}}$ & $\mathrm{ET}_{\mathrm{RES}}$ & $\mathrm{ET}_{\mathrm{EC} \_\mathrm{BR}}$ \\
\hline $2003-2004$ & $1,368 \mathrm{~mm}$ & $1,422 \mathrm{~mm}$ & $965 \mathrm{~mm}$ & $1,552 \mathrm{~mm}$ & $1,495 \mathrm{~mm}$ \\
& $142 \%$ & $147 \%$ & $100 \%$ & $161 \%$ & $155 \%$ \\
$2004-2005$ & $1,210 \mathrm{~mm}$ & $1,302 \mathrm{~mm}$ & $1,127 \mathrm{~mm}$ & $1,440 \mathrm{~mm}$ & $1,343 \mathrm{~mm}$ \\
& $107 \%$ & $116 \%$ & $100 \%$ & $128 \%$ & $119 \%$ \\
\hline
\end{tabular}

$G S$ growing season, $E C, B R$ measurements from eddy correlation technique and Bowen ratio method, respectively, REG, RES, EC_BR regression, residual and the combination methods, respectively

Bowen ratio (BR) techniques. While EC systems are expensive, BR method is cheaper and the instrumental is easier to operate. The classical BR estimations showed 4 and $15 \%$ more seasonal ET compared to the measurements from the EC system for a wetter and a drier growing season, respectively.

The EC system in the irrigated mango orchard showed an energy balance closure gap of $12 \%$ at daily timescale. This is low compared to the international literature. Many explanations for this problem exist, and it is reasonable to conclude that the EC system cannot be used as a high reliable way to measure the latent heat flux in irrigated crops without adequate correction procedures. Evapotranspiration research should therefore develop appropriate interpretation and correction procedures. The current paper is a contribution in that respect, and much more research is needed covering different irrigated surfaces.

The four methods, Bowen ratio (BR), residual (RES), combination (EC_BR), and Bowen ratio (BR), showed a reasonable agreement with EC measurements, although the BR method was less sensitive to phenological changes throughout the mango-growing seasons compared to those which uses EC measurements. The simple multiple linear regression method appears to be very helpful in identifying the components of the energy balance that need adjustments to force the energy balance to close, mainly when the soil heat flux is difficult to measure accurately. It is a more elegant solution than the Bowen ratio of EC fluxes that implicitly assumes that sensible and latent heat fluxes measured with an EC system have the same level of confidence and do not consider the accuracy of the other energy balance terms.

Since there is no consensus in the literature on denoting one particular flux term as the source of error, we believe that the REG method is the most unbiased solution. Applying this last method for the drier season of the mango orchard as a reference, the regression coefficients were 0.93, 0.87 and 5.06 for latent, sensible and soil heat fluxes, respectively, considering all periods of the day. This suggests that the latent heat flux from the kripton hygrometer was measured with relatively more accuracy than the sensible heat flux from the sonic anemometer in conditions of low precipitation. While there were sound reasons to move away from lysimeters to turbulent flux measurement systems in the eighties and nineties, this study shows that the perfect method for direct field measurement of the latent heat flux does not exist yet. This should be understood by the irrigation, hydrological, soil physical, crop yield and remote sensing modelling community, because it implies that modelled data of evapotranspiration may be as appropriate as the measured ones for specific purposes.

Acknowledgments This research was supported by CAPES (Ministry of Education-Brazil) and FACEPE (Science and Technology Foundation of Pernambuco state, Brazil). CAPES is acknowledged for granting a full scholarship for the Ph.D. of the first author and FACEPE for the financial support to the actual project on water productivity in the Low-Middle São Francisco river basin, Brazil.

\section{References}

Ahmad MD, Bastiaanssen WGM, Feddes RA (2002) Sustainable use of groundwater for irrigation: a numerical analysis of subsoil water flux, John Wiley \& Sons. Irrig Drain 51(3):227-241

Allen R (2008) Quality assessment of weather data and micrometeorological flux-impacts on evapotranspiration calculation. J Agric Meteorol 64(4):191-204

Allen RG, Pereira LS, Raes D, Smith M (1998) Crop evapotranspiration. Guidelines for computing crop water requirements. FAO Irrigation and Drainage Paper 56, Rome, Italy, 300 pp

Azevedo PV de, da Silva BB, da Silva VPR (2003) Water requirements of irrigated mango orchards in northeast Brazil. Agric Water Manage 58:241-254

Baldocchi D, Falge E, Gu L, Olson R, Hollinger D, Running S, Anthoni P, Bernhofer C, Davis K, Evans R, Fuentes J, Goldstein A, Katul G, Law B, Lee X, Malhi Y, Meyers T, Munger W, Oechel W, Paw UKT, Pilegaard K, Schmid HP, Valentini R, Verma S, Vesala T, Wilson K, Wofsy S (2001) FLUXNET: a new tool to study the temporal and spatial variability of ecosystem-scale carbon dioxide, water vapour, and energy flux densities. Bull Am Meteorol Soc 82(11):2415-2434

Bastiaanssen WGM, Allen RG, Droogers P, D'urso G, Steduto P (2007) Twenty-five years modelling irrigated and drained soils: state of the art. Agric Water Manage 92(3):111-125

Bastiaanssen WGM, Bingfang W, Olson DC, Liping J (2008) Water saving strategies on the northwest China plain. Stockholm Water Front 1:12-13

Beringer J, Tapper NJ (2000) The influence of subtropical cold fronts on the surface energy balance of a semi-arid site. J Arid Environ 44:437-450

Castellvi F, Snyder RL, Baldocchi DD (2008) Surface energy-balance closure over rangeland grass using the eddy covariance method and surface renewal analysis. Agric For Meteorol 148:11471160

Chehbouni A, Ezzahar J, Watts C, Rodriguez J-C, Garatuza-Payan J (2006) Estimating area-averaged surface fluxes over contrasted agricultural patchwork in a semi-arid region. In: Hill J, Roder A (eds) Advances in remote sensing and geoinformation processing for land degradation assessment. Taylor and Francis, London 
Cleverly JR, Dahm CN, Thibaut JR, Gilroy DJ, Coonrod JEA (2002) Seasonal estimates of actual evapotranspiration from Tamarix ramosissima stands using three-dimensional eddy correlation. J Arid Environ 52:181-197

Denmead OT, McIlroy IC (1970) Measurement of non-potential evaporation from wheat. Agric Meteorol 7:285-302

Doorenbos J, Pruitt WO (1977) Guidelines for predicting crop water requirements, 2nd edn. FAO, Rome (FAO Irrigation and Drainage Paper 24)

Droogers P, Immerzeel WW, Lorite IJ (2010) Estimating actual irrigation application by remotely sensed evapotranspiration observations. Agric Water Manage 97(9):1351-1359

Dugas WA, Fritschen LJ, Gay LW, Held AA, Matthias AD, Reicosky C, Steduto P, Steiner JL (1991) Bowen ratio, eddy correlation and portable chamber measurements of sensible and latent heat flux over irrigated spring wheat. Agric For Meteorol 56:1-20

Fereres E, Soriana MA (2007) Deficit irrigation for reducing agricultural water use. J Exp Bot 58(2):147-159

Heilman JL, Mcinnes KJ, Savage MJ, Gesh RW, Lascano RJ (1994) Soil and canopy energy balances in a west Texas vineyard. Agric For Meteorol 71:99-114

Heilman JL, Mcinnes KJ, Gesh RW, Lascano RJ, Savage MJ (1996) Effects of trellising on the energy balance of the vineyard. Agric For Meteorol 81:79-93

Heusinkveld BG, Jacobs AFG, Hotslag AAM, Berkowicz SM (2004) Surface energy balance closure in an arid region: role of soil heat flux. Agric For Meteorol 122:21-37

Hiyama T, Strunin MA, Tanaka H, Ohta T (2007) The development of local circulations around the Lena River and their effect on tower-observed energy imbalance. Hydrol Proc 21:2038-2048

Hoedjes JCB, Zuurbier RM, Watts CJ (2002) Large aperture scintillometer used over a homogeneous irrigated area, partly affected by regional advection. Bound Lay Meteorol 105:99-117

Humphreys ER, Black TA, Ethier GJ, Drewitt GB, Spittlehouse DL, Jork EM, Nesic Z, Livingston NJ (2003) Annual and seasonal variability of sensible and latent heat fluxes above a coastal Douglas-fir forest, British Columbia, Canada. Agric For Meteorol 115:109-125

Inman-Bamber NG, McGlinchey MG (2003) Crop coefficients and water-use estimates for sugarcane based on long-term Bowen ratio energy balance measurements. Field Crops Res 83:125-138

Jensen ME, Burman RD, Allen RG (ed) (1990) Evapotranspiration and irrigation water requirements. ASCE manuals and reports on engineering practices no. 70, American Social Civil Engineers, New York, NY, $360 \mathrm{p}$

Lee X, Yu Q, Sun X, Liu J, Min Q, Liu Y, Zhang X (2004) Micrometeorological fluxes under the influence of regional and local advection: a revisit. Agric For Meteorol 122:11-124

Lopes PMO, da Silva BB, de Azevedo PV, da Silva VPR, Teixeira AHC, Soares JM, Sobrinho JE (2001) Balanço de energia num pomar de mangueiras irrigado. Rev Bras de Agrometeorol 9:1-8

Lund MR, Soegaard H (2003) Modelling of evaporation in a sparse millet using a two source model including sensible heat advection within the canopy. J Hydrol 280:124-144

Moore CJ (1986) Frequency response corrections for eddy correlation systems. Bound Lay Meteorol 37:17-35

Ohta T, Hiyama T, Tanaka H, Kuwada T, Maximov TC, Ohata T, Fukushima Y (2001) Seasonal variation in the energy and water exchanges above and below a larch forest in eastern Siberia. Hydrol Proc 15:1459-1476

Olejnik J, Eulenstein F, Kedziora A, Werner A (2001) Evaluation of a water balance model using data for bare soil and crop surfaces in Middle Europe. Agric For Meteorol 106:105-116

Oliver HR, Sene KJ (1992) Energy and water balances of developing vines. Agric For Meteorol 61:167-185
Ortega-Farias S, Carrasco M, Olioso A, Acevedo C, Poblete C (2007) Latent heat flux over cabernet sauvignon vineyard using the Shuttleworth and Wallace model. Irrig Sci 25:161-170

Paço TA, Ferreira MI, Conceição N (2006) Peach orchard evapotranspiration in a sandy soil: comparison between eddy correlation measurements and estimates by the FAO 56 approach. Agric Water Manage 85(3):305-313

Papale D, Reichstein M, Aubinet M, Canfora E, Bernhofer C, Kutsch W, Longdoz B, Rambal S, Valentini R, Vesala T, Yakir D (2006) Towards a standardized processing of net ecosystem exchange measured with eddy covariance technique: algorithms and uncertainty estimation. Biogeosciences 3(4):571-583

Paw UKT, Baldocchi DD, Meyers TP, Wilson KB (2000) Corrections of eddy correlation measurements incorporating both advective effects and density fluxes. Bound Lay Meteorol 97:487-511

Prueger JH, Kustas WP, Hipps LE, Hatfield JL (2004) Aerodynamic parameters and sensible heat flux estimates for a semi-arid ecosystem. J Arid Environ 57:87-100

Rana G, Katerji N, de Lorenza F (2005) Measuring and modelling of evapotranspiration of irrigated citrus orchard under Mediterranean conditions. Agric For Meteorol 128:199-209

Savage MJ, Everson CS, Metelerkamp BR (2009) Bowen ratio evaporation measurement in a remote montane grassland: data integrity and fluxes. J Hydrol 376:249-260

Scott CA, Bastiaanssen WGM, Ahmad MD (2003a) Mapping root zone soil moisture using remotely sensed optical imagery. ASCE J Irrig Drain Eng 129:326-335

Scott RL, Watts C, Payan JG, Edwards E, Goodrich DC, Williams D, Shuttleworth WJ (2003b) The understory and overstory partitioning of energy and water fluxes in an open canopy, semiarid woodland. Agric For Meteorol 114:127-139

Sene KJ (1994) Parameterizations for energy transfers from a sparse vine crop. Agric For Meteorol 71:1-18

Shuttleworth WJ, Gurney RJ, Hsu AY, Ormsby JP (1989) FIFE: the variation in energy partition at surface flux sites. In: Proceedings of the IAHS third international assembly, IAHS Publication No. 186, pp 67-74

Simmons LJ, Wang J, Sammis TW, Miller DR (2007) An evaluation of two inexpensive energy-balance techniques for measuring water use in flood-irrigated pecans (Carya illioinensis). Agric Water Manage 88:181-191

Spano D, Snyder RL, Duce P, Paw UKT (2000) Estimating sensible and latent heat flux densities from grapevine canopies using surface renewal. Agric For Meteorol 104:171-183

Stull RB (1998) An introduction to boundary layer meteorology. Kluwer Academic Publishers, Boston

Tanaka H, Hiyama T, Kobayashi N, Yabuki H, Ishii Y, Desyatkin RV, Maximov TC, Ohta T (2008) Energy balance and its closure over a young larch forest in eastern Siberia. Agric For Meteorol 148:1954-1967

Tanner BD, Swiatek E, Greene JP (1993) Density fluctuations and use of the krypton hygrometer in surface flux measurements. In: Proceedings of the national irrigation drainage engineering, 21-23 July 1993, Park City, UT. ASCE, New York, NY

Teixeira AH de C (2009) Water productivity assessments from field to large scale: a case study in the Brazilian semi-arid region. LAP Lambert Academic Publishing, Saarbrücken

Teixeira AH de C, Bastiaanssen WGM, Bassoi LH (2007) Crop water parameters of irrigated wine and table grapes to support water productivity analysis in Sao Francisco River basin, Brazil. Agric Water Manage 94:31-42

Teixeira AH de C, Bastiaanssen WGM, Moura MSB, Soares JM, Ahmad M-ud-D, Bos MG (2008a) Energy and water balance measurements for water productivity analysis in irrigated mango trees, Northeast Brazil. Agric For Meteorol 148:1524-1537 
Teixeira AH de C, Bastiaanssen WGB, Ahmad M-ud-D, Bos MG (2008b) Analysis of energy fluxes and vegetation-atmosphere parameters in irrigated and natural ecosystems of semi-arid Brazil. J Hydrol 362:110-127

Testi L, Villalobos FJ, Orgaz F (2004) Evapotranspiration of a young olive orchard in southern Spain. Agric For Meteorol 121:1-18

Testi L, Orgaz F, Villalobos FJ (2006) Variations in bulk canopy conductance of an irrigated olive (Olea europaea L.) orchard. Environ Exp Bot 55:15-28

Trambouze W, Bertuzzi P, Voltz M (1998) Comparison of methods for estimating actual evapotranspiration in a row-cropped vineyard. Agric For Meteorol 81:193-208

Twine TE, Kustas WP, Norman JM, Cook DR, Houser PR, Meyers TP, Prueger JH, Starks PJ, Wesely ML (2000) Correcting eddycorrelation flux estimates over grassland. Agric For Meteorol 103:279-300

Unland HE, Houser PR, Shuttleworth WJ, Yand Z (1996) Surface flux measurement and modelling at a semi-arid Sonoran Desert site. Agric For Meteorol 82:119-153

van Dijk A, Moene AF, de Bruin R (2004a) The principles of surface flux physics: theory, practice and description of the Ecpack library, Internal Report, Meteorology and Air Quality Group, Wageningen University, Wageningen, The Netherlands, 99 pp

van Dijk AIJM, Bruijnzeel LA, Schellekens J (2004b) Micrometeorology and water use of mixed crops in upland West Java. Indonesia Agric For Meteorol 124:31-49
Verma SB, Rosemberg NJ, Blad BL (1978) Turbulent exchange coefficients for sensible heat and water vapour under advective conditions. J Appl Meteorol 17:330-338

Vilalolobos FJ, Testi L, Rizzalli R, Orgaz F (2004) Evapotranspiration and crop coefficients of irrigated garlic (Allium sativum L.) in a semi-arid climate. Agric Water Manage 64:233-249

Webb EK, Pearmen GL, Leuning R (1980) Correction of flux measurements for density effects due to heat and water vapour transfer. Q J R Meteorol Soc 106:85-100

Wilczak JM, Oncley SP, Stage SA (2001) Sonic anemometer tilt correction algorithms. Bound-Lay Meteorol 99:127-150

Wilson K, Goldstein A, Falge E, Aubinet M, Baldocchi D, Berbigier P, Bernhofer C, Ceulemans R, Dolman H, Field C, Grelle A, Ibrom A, Law BE, Kowalski A, Meyers T, Moncrieff J, Monson R, Oechel W, Tenhunen J, Valentini R, Verma S (2002) Energy balance closure at Fluxnet sites. Agric For Meteorol 113:223-243

Wolf A, Saliendra N, Akshalov K, Johnson DA, Laca E (2008) Effects of different eddy covariance correction schemes on energy balance closure and comparisons with the modified Bowen ratio system. Agric For Meteorol 148:942-952

Wright JL (1982) New evapotranspiration crop coefficients. J Irrig Drain Div ASCE 108(IR2):57-74

Yunusa IAM, Walker RR, Lu P (2004) Evapotranspiration components from energy balance, sapflow and microlysimetry techniques for an irrigated vineyard in inland Australia. Agric For Meteorol 127:93-107 